\title{
Light-Driven Calcium Signals in Mouse Cone Photoreceptors
}

\author{
Tao Wei, ${ }^{1,2}$ Timm Schubert, ${ }^{1,2 *}$ François Paquet-Durand, ${ }^{2 *}$ Naoyuki Tanimoto, ${ }^{3}$ Le Chang, ${ }^{1,5}$ Katja Koeppen, ${ }^{4}$ \\ Thomas Ott, ${ }^{6}$ Oliver Griesbeck, ${ }^{7}$ Mathias W. Seeliger, ${ }^{3}$ Thomas Euler, ${ }^{1,2}$ and Bernd Wissinger ${ }^{4}$ \\ ${ }^{1}$ Centre for Integrative Neuroscience, and ${ }^{2}$ Institute for Ophthalmic Research, ${ }^{3}$ Division of Ocular Neurodegeneration, and ${ }^{4}$ Molecular Genetics Laboratory, \\ Centre for Ophthalmology, University of Tübingen, 72076 Tübingen, Germany, ${ }^{5}$ Institute of Biophysics, Chinese Academy of Sciences, 100101 Beijing, \\ China, ${ }^{6}$ Transgenic Animals Core Facility, University Clinics, 72076 Tübingen, Germany, and ${ }^{7}$ Max Planck Institute of Neurobiology, 82152 Martinsried, \\ Germany
}

Calcium mediates various neuronal functions. The complexity of neuronal $\mathrm{Ca}^{2+}$ signaling is well exemplified by retinal cone photoreceptors, which, with their distinct compartmentalization, offer unique possibilities for studying the diversity of $\mathrm{Ca}^{2+}$ functions in a single cell. Measuring subcellular $\mathrm{Ca}^{2+}$ signals in cones under physiological conditions is not only fundamental for understanding cone function, it also bears important insights into pathophysiological processes governing retinal neurodegeneration. However, due to the proximity of light-sensitive outer segments to other cellular compartments, optical measurements of light-evoked Ca ${ }^{2+}$ responses in cones are challenging. We addressed this problem by generating a transgenic mouse (HR2.1:TN-XL) in which both short- and middlewavelength-sensitive cones selectively express the genetically encoded ratiometric $\mathrm{Ca}^{2+}$ biosensor TN-XL. We show that $H R 2.1: T N-X L$ allows recording of light-evoked $\mathrm{Ca}^{2+}$ responses using two-photon imaging in individual cone photoreceptor terminals and to probe phototransduction and its diverse regulatory mechanisms with pharmacology at subcellular resolution. To further test this system, we asked whether the classical, nitric oxide (NO)-soluble guanylyl-cyclase (sGC)-cGMP pathway could modulate Ca ${ }^{2+}$ in cone terminals. Surprisingly, NO reduced $\mathrm{Ca}^{2+}$ resting levels in mouse cones, without evidence for direct sGC involvement. In conclusion, $H R 2.1: T N-X L$ mice offer unprecedented opportunities to elucidate light-driven $\mathrm{Ca}^{2+}$ dynamics and their (dys)regulation in cone photoreceptors.

\section{Introduction}

Retinal cone photoreceptors (cones) are highly specialized transducers that convert photon flux into electrical signals (for review, see Pugh and Lamb, 1993). Cones are depolarized in darkness, with high intracellular calcium concentration $\left(\left[\mathrm{Ca}^{2+}\right]\right)$ in the synaptic terminal to enable sustained glutamate release using a specialized synaptic machinery, the ribbon complex (for review, see Sterling and Matthews, 2005). Light triggers a complex transduction cascade (Pugh and Lamb, 1993), leading to hyperpolarization of the cone, subsequent reduction of terminal $\left[\mathrm{Ca}^{2+}\right]$ (Borghuis et al., 2011), and decrease in glutamate release (Choi et al., 2005). In addition to mediating transmitter release, $\mathrm{Ca}^{2+}$ plays a key role in regulating many intracellular processes in cones in a highly compartmentalized manner. Changes in intracellular $\left[\mathrm{Ca}^{2+}\right]$ modulate the amplifica-

Received Dec. 23, 2011; revised March 2, 2012; accepted March 31, 2012.

Author contributions: T.W., T.S., F.P.-D., N.T., M.W.S., T.E., and B.W. designed research; T.W., N.T., K.K., and T.O. performed research; 0. G. contributed unpublished reagents/analytic tools; T.W., N.T., L.C., and T.E. analyzed data; T.W., T.S., F.P.-D., N.T., T.E., and B.W. wrote the paper.

This work was supported by the Deutsche Forschungsgemeinschaft (EXC 307 to T.E., T.S.; F0R701 to L.C.; KF0 134 to M.W.S., B.W.), the Bundesministerium für Bildung und Forschung (via the Bernstein Center for Computational Neuroscience Tübingen, FKZ:01GQ1002 to T.E.), the Tistou und Charlotte Kerstan Stiftung (to T.W., F.P-D.), and the Max Planck Society (to 0.G.). We thank Britta Baumann, Gordon Eske, and Norman Rieger for excellent technical assistance and Tom Baden and Thomas Ladewig for helpful discussions.

The authors declare no competing financial interests.

*T.S. and F.P.-D. contributed equally to this work.

Correspondence should be addressed to Thomas Euler, Centre for Integrative Neuroscience/Centre for Ophthalmology, University of Tübingen, Otfried-Müller-Strasse 25, 72076 Tübingen, Germany. E-mail: thomas.euler@cin.uni-tuebingen.de.

DOI:10.1523/JNEUROSCI.6432-11.2012

Copyright $(2012$ the authors $\quad 0270-6474 / 12 / 326981-14 \$ 15.00 / 0$ tion rate of phototransduction in the outer segment (OS), energy metabolism in the inner segment (IS), as well as gene expression in the soma (Korenbrot, 1995; Koutalos and Yau, 1996; Fain et al., 2001; Krizaj and Copenhagen, 2002; Johnson et al., 2007). Moreover, aberrations in cone $\mathrm{Ca}^{2+}$ dynamics are tightly connected to pathophysiological processes during photoreceptor neurodegeneration (Chang et al., 1993; Sancho-Pelluz et al., 2008).

In recent years, $\mathrm{Ca}^{2+}$ signaling in photoreceptors was investigated in different vertebrate species, including amphibians (Sheng et al., 2007; Choi et al., 2008) and mammals (Johnson et al., 2007), using optical methods and AM-ester loading (Tsien, 1981) of synthetic fluorescent $\mathrm{Ca}^{2+}$ indicators. While this approach provided valuable estimates of steady-state $\left[\mathrm{Ca}^{2+}\right]$ in rods and cones, AM-dye loading is problematic since it requires organic solvents (e.g., DMSO), it is strongly species- and age-dependent, and produces formaldehyde as a consequence of the intracellular AM-esters cleavage (Tsien et al., 1982; Rink and Pozzan, 1985). More importantly, synthetic indicators cannot be targeted to specific neuron types. This is problematic since retinal Müller glia tends to accumulate AMdyes, effectively masking neuronal signals. Among the synthetic $\mathrm{Ca}^{2+}$ indicators, fura- 2 is a typical choice, because it is ratiometric and therefore allows measurements independent of dye concentration and fluorescence intensity. However, as the excitation wavelengths for fura-2 evoke substantial light responses $(\sim 700 / 760 \mathrm{~nm}$ for two-photon excitation), measurements require short exposure times, which limits the ability of probing photoreceptor $\mathrm{Ca}^{2+}$ with light stimuli under physiological conditions.

Here, we generated a transgenic mouse (HR2.1:TN-XL) that expresses the genetically encoded $\mathrm{Ca}^{2+}$ biosensor TN-XL (Mank 
et al., 2006) under the control of the human red opsin promoter (HR2.1) (Wang et al., 1992). TN-XL is a Förster resonance energy transfer-based ratiometric $\mathrm{Ca}^{2+}$ sensor composed of enhanced cyan fluorescent protein (eCFP) as donor and citrine as acceptor, with mutated troponin $\mathrm{C}$ from chicken skeletal muscle serving as $\mathrm{Ca}^{2+}$ binding moiety (Mank et al., 2006). Due to its comparatively low $\mathrm{Ca}^{2+}$ affinity $\left(K_{\mathrm{D}}: \sim 0.7 \mu \mathrm{M}\right.$ in vivo, $2.2 \mu \mathrm{M}$ in vitro) (Hendel et al., 2008), TN-XL is expected to have a minimal effect on intrinsic $\mathrm{Ca}^{2+}$ buffering capacity.

In this study, we demonstrate that HR2.1:TN-XL mice are well suited to characterize light-driven and pharmacologically evoked $\mathrm{Ca}^{2+}$ changes in single cone photoreceptors with subcellular resolution and therefore allow investigating different aspects of cone function. Using pharmacological stimulation, we show that the largest $\mathrm{Ca}^{2+}$ changes occur in cone synaptic terminals, while $\left[\mathrm{Ca}^{2+}\right]$ levels in soma and IS are well controlled. By modulating components of the transduction and synaptic signaling cascades, we show that cone light responses allow probing different aspects of cone function with high sensitivity, exemplifying a few of the potential applications for our HR2.1:TN-XL mouse.

\section{Materials and Methods}

Generation of the HR2.1:TN-XL construct. A plasmid containing the calcium biosensor TN-XL (Mank et al., 2006) under the control of the cytomegalovirus (CMV) promoter was kindly provided by Oliver Griesbeck [Max Planck Institute (MPI) of Neurobiology, Martinsried, Germany]. To target expression of TN-XL in cone photoreceptors, we replaced the CMV promoter with HR2.1, a functionally verified version of the human red opsin promoter (Wang et al., 1992) kindly provided by Jeremy Nathans (Howard Hughes Medical Institute, Baltimore MD). The integrity of the resulting HR2.1:TN-XL construct was confirmed by DNA sequencing using BigDye Terminator V3.1 Kit (Applied Biosystems). Before microinjection into fertilized eggs, the HR2.1:TN-XLcontaining fragment was excised from the vector backbone by restriction enzyme digestion and isolated by electrophoretic separation on an agarose gel. The HR2.1:TN-XL fragment was excised from the gel and purified using the QIAquick Gel Extraction Kit (Qiagen). Purified DNA was dissolved in microinjection buffer containing $0.1 \mathrm{~mm}$ EDTA and $10 \mathrm{~mm}$ Tris-HCl, $\mathrm{pH}$ 7.5, and DNA quantity was determined by using a NanoDrop ND-1000 spectrometer (Thermo Fisher Scientific). In addition, an aliquot of the DNA was subjected to electrophoresis on a $1.5 \%$ agarose gel along with a series of a DNA standard $(2,5,10,20,50$ and 100 ng of $\lambda$ HindIII/EcoRI standard). The DNA samples were stored at $4^{\circ} \mathrm{C}$ before use.

Generation of the HR2.1:TN-XL transgenic mouse line. All procedures were performed in accordance with the law on animal protection issued by the German Federal Government (Tierschutzgesetz) and approved by the institutional committee on animal experimentation of the University of Tübingen. Transgenic founder mice (of either sex) were generated by direct microinjection of the HR2.1:TN-XL construct into the pronuclei of fertilized ova (Gordon and Ruddle, 1981). Manipulated zygotes were transplanted into the oviducts of pseudopregnant NMRI foster mice on the day of injection or as two-cell embryos on the next day. Founder mice were identified by PCR specific for the HR2.1:TN-XL construct and then cross-bred with C57BL/6J wildtype mice. A universal probe library-based quantitative PCR approach (Roche) was used to estimate the transgene copy number and copy number stability in subsequent generations. The offspring of founder mice were analyzed for TN-XL expression in cones (using fluorescence microscopy, see Immunohistochemistry and fluorescence microscopy, below). Retinal expression of TN-XL was observed in only one of the 10 founder lines tested. This HR2.1:TN-XL line had $\sim 10-15$ transgene copies per haploid genome, probably inserted at a single site since copy number as determined by qPCR was stable during multiple generations of outcrosses. This line was bred to homozygosity for the transgene insertion and was used for all subsequent histological and physiological experiments.
Animals and tissue preparation. Animals were housed under a standard $12 \mathrm{~h}$ day/night rhythm. For retinal dissection, the animals (of either sex) were anesthetized using Isoflurane (Baxter) and killed by cervical dislocation.

For immunohistochemistry, 8-week-old HR2.1:TN-XL animals were used. After the mice were killed, the eyes were marked at the nasal side to maintain retinal orientation and quickly enucleated. The anterior part of the eye, including lens and vitreous body was removed. Then the posterior part of the eye, including the retina, was fixated in $4 \%$ paraformaldehyde diluted in PBS containing the following (in mM): $20 \mathrm{NaH}_{2} \mathrm{PO}_{4}, 80$ $\mathrm{Na}_{2} \mathrm{HPO}_{4}, 154 \mathrm{NaCl}, \mathrm{pH} 7.4$, for $45 \mathrm{~min}$ at $4^{\circ} \mathrm{C}$. Then the retinas were washed with PBS and cryoprotected in increasing concentrations of sucrose $(10,20$, and $30 \%)$. For vertical sections, fixated eye cups were embedded in tissue-freezing medium, frozen in liquid $\mathrm{N}_{2}$, and cut into 12 $\mu \mathrm{m}$ sections using a cryostat (CM3050S; Leica Microsystems). The sections were collected on glass slides and stored at $-20^{\circ} \mathrm{C}$ for later use. For retinal whole mounts, retinas were placed on filter paper, fixated, and further processed.

For calcium imaging, acute retinal slices were prepared from 4- to 7-week old HR2.1:TN-XL mice. For experiments involving light stimuli (two-photon imaging), the animals were dark-adapted for at least $2 \mathrm{~h}$ before dissection. After the mice were killed, the eyes were quickly enucleated and hemisected in carboxygenated $\left(95 \% \mathrm{O}_{2}, 5 \% \mathrm{CO}_{2}\right)$ artificial CSF (ACSF) solution containing the following (in mM): $125 \mathrm{NaCl}, 2.5$ $\mathrm{KCl}, 2 \mathrm{CaCl}_{2}, 1 \mathrm{MgCl}_{2}, 1.25 \mathrm{NaH}_{2} \mathrm{PO}_{4}, 26 \mathrm{NaHCO}_{3}$, and 20 glucose, $\mathrm{pH}$ 7.4. Remaining vitreous was carefully removed using forceps before the retina was dissected from the eyecup. The retinas were cut in half, flattened by cutting off their edges, and put onto filter paper $(0.8 \mu \mathrm{m}$ pore size; Millipore) with the photoreceptor layer facing up. Vertical slices $(200 \mu \mathrm{m})$ were cut by using a custom-made tissue chopper (Werblin, 1978). Slices with the filter paper attached were stabilized using vacuum grease (Dow Corning) on plastic coverslips. This allowed the storage of slices in a holding chamber with carboxygenated ACSF at room temperature (RT) before they were placed under the microscope. In the respective recording chambers of the two microscopes (see Imaging of light-evoked calcium changes by two-photon microscopy, below), the slices were perfused constantly with temperated $\left(\sim 36^{\circ} \mathrm{C}\right)$ carboxygenated ACSF.

Immunohistochemistry and fluorescence microscopy. Retinal sections stored at $-20^{\circ} \mathrm{C}$ were desiccated at $37^{\circ} \mathrm{C}$ and subsequently rehydrated in PBS. The slices were then incubated for $1 \mathrm{~h}$ at RT in blocking solution containing $0.3 \%$ PBS-T, $1 \%$ BSA, and $5-10 \%$ corresponding normal serum from the host animals (goat or rabbit) of which the respective secondary antibodies were obtained. Primary antibodies included rabbit anti-blue opsin (1:200; catalog no. AB5407, Millipore Bioscience Research Reagents), rabbit anti-red/green opsin (1:200; catalog no. AB5405, Millipore Bioscience Research Reagents), mouse anti-green fluorescence protein (anti-GFP; 1:200; catalog no. NB600-597; Novus Biologicals), and rabbit anti-soluble guanylyl cyclase (anti-sGC; 1:200; catalog no. AB50238, Abcam) and were diluted in blocking solution and applied overnight at $4^{\circ} \mathrm{C}$. After incubation with primary antibodies, sections were washed four times for $5 \mathrm{~min}$ in PBS and then incubated for $1 \mathrm{~h}$ at RT with secondary antibodies (Alexa Fluor 488 and 660; Invitrogen) diluted 1:500 in PBS. After washing six times in PBS, the sections were mounted using Vectashield (Vector).

Nitric oxide synthase (NOS) diaphorase assay (Hope et al., 1991) was performed by incubating rehydrated retinal tissue sections for $4 \mathrm{~h}$ at $37^{\circ} \mathrm{C}$ in $0.3 \%$ PBS-T, $0.7 \mathrm{~mm}$ NADPH, $0.25 \mathrm{~mm}$ Nitrobluetetrazolium (both from Sigma-Aldrich). After washing three times in PBS, sections were mounted using Vectashield.

Standard fluorescent and translucent microscopy was performed on an Imager Z1 Apotome Microscope (Zeiss) equipped with a Zeiss Axiocam digital camera, Zeiss objectives (Plan-APOCHROMAT $5 \times 1$ $0.16,20 \times / 0.8$ and EC Plan-NEOFLUAR $40 \times / 1.3$ oil), and Zeiss filter sets (filter set 38 for Alexa 488, excitation 470/40 nm, emission 525/50 nm; filter set 50 for Alexa 660, excitation 640/30 nm, emission 690/50 nm). Images were acquired with Zeiss Axiovision 4.8 software and processed using Canvas (ACD Systems International). 
Electroretinograms measurements. To test whether expression of the $\mathrm{Ca}^{2+}$ biosensor in cones affects in vivo photoreceptor function in the HR2.1:TN-XL mice, electroretinograms (ERGs) were recorded binocularly from animals at the ages of 1 and 3 months, as described previously (Seeliger et al., 2001; Tanimoto et al., 2009). Mice were anesthetized using ketamine $(66.7 \mathrm{mg} / \mathrm{kg}$ body weight $)$ and xylazine $(11.7 \mathrm{mg} / \mathrm{kg}$ body weight). The pupils were dilated and single-flash ERG responses were obtained under scotopic (dark-adapted overnight) and photopic (lightadapted with a background illumination of $30 \mathrm{~cd} / \mathrm{m}^{2}$ starting $10 \mathrm{~min}$ before recording) conditions. Single white-flash stimuli ranged from -4 to $1.5 \log \mathrm{cd} \cdot \mathrm{s} / \mathrm{m}^{2}$ under dark-adapted and from -2 to $1.5 \log \mathrm{cd} \cdot \mathrm{s} / \mathrm{m}^{2}$ under light-adapted conditions. Ten responses were averaged with interstimulus intervals of $5 \mathrm{~s}$ (for -4 to $-0.5 \log \mathrm{cd} \cdot \mathrm{s} / \mathrm{m}^{2}$ ) or $17 \mathrm{~s}$ (for 0 to 1.5 $\log \mathrm{cd} \cdot \mathrm{s} / \mathrm{m}^{2}$ ). Responses to trains of flashes (flicker) for a fixed intensity $\left[0.5 \log \mathrm{cd} \cdot \mathrm{s} / \mathrm{m}^{2}\right.$; the International Society for Clinical Electrophysiology of Vision standard flash intensity (Marmor et al., 2004)] at 18 and 20 $\mathrm{Hz}$ were obtained under dark-adapted conditions. Flicker responses were averaged 30 times. Bandpass filter cutoff frequencies were 0.3 and $300 \mathrm{~Hz}$ for all ERG recordings. The Mann-Whitney rank sum test was used to test for statistical significance of differences in a-wave and b-wave ERG amplitudes in HR2.1:TN-XL $(n=6)$ and wt (littermates, $n=6)$ mice.

Imaging of light-evoked calcium changes by two-photon microscopy. We used a custom-built two-photon (2P) microscope (Denk et al., 1990) as described earlier (Euler et al., 2009; Breuninger et al., 2011). In brief, the system was equipped with a mode-locked Ti/sapphire laser (MaiTai-HP DeepSee; Newport Spectra-Physics) tuned to $\sim 860 \mathrm{~nm}$, two detection channels for fluorescence imaging of eCFP [483 band pass (BP) 32; AHF] and citrine (535 BP 50; AHF) and a $20 \times$ water-immersion objective (XLUMPlanFL 20× water-immersion, $0.95 \mathrm{NA}$; Olympus). Image acquisition was performed using customized software (CfNT, by Michael Müller, MPI for Medical Research, Heidelberg, Germany) and by taking $128 \times 8$ pixel images (at $62.5 \mathrm{~Hz}$ frame rate) restricted to the row of cone pedicles in the outer plexiform layer (see Fig. $3 A, C$ ). This way, bleaching of the light-sensitive cone outer segments by the scanning laser could be largely avoided.

Light stimulation. A custom-built dichromatic light stimulator (Breuninger et al., 2011) was mounted below the recording chamber and consisted of two bandpass-filtered (UV: 360 BP 12; green: 578 BP 10; AHF) LEDs. Their light was combined by a beam-splitter (400 DCLP; AHF) focused by an achromatic air condenser lens (0.8 NA, HDIC; Zeiss) and projected through the glass bottom of the recording chamber. The LEDs were driven by an open-source microprocessor board (http:// arduino.cc). Because the UV LED evoked weak but detectable fluorescence in the tissue, we synchronized the LED on-time with the $2 \mathrm{P}$ microscope's scanner retrace and thereby prevented stimulation artifacts during the acquisition time fraction of a scan line (when the laser scanned the cone pedicles). A combination of dichroic mirrors in front of the photomultipliers and in the detection path prevented light from the stimulation LEDs from interfering with the fluorescence detection directly (for details, see Euler et al., 2009).

Two light stimulation protocols were used. In the first protocol (see Figs. $3 C, 4 B, C$ ), bright $1 \mathrm{~s}$ flashes were presented every $5 \mathrm{~s}$ and repeated $7-10$ times. During the flashes, the intensity (as photoisomerization rate, $10^{3} \cdot \mathrm{P} \cdot \mathrm{s}^{-1}$ per cone) was stepped from background level to 13.0 and 12.8 for M- and S-opsins, respectively. Here, background level meant that the stimulator LEDs were off but the excitation laser was scanning. Since the laser light scattered in the tissue, this provided a low basal illumination (see Fig. $3 C$ ), to which the cone photoreceptors adapted within tens of seconds. In the second protocol (see Fig. 4A), bright and dark flashes ( $1 \mathrm{~s}$ duration, every $5 \mathrm{~s}, 7$ repeats) were presented by stepping the intensity (in $10^{3} \cdot \mathrm{P} \cdot \mathrm{s}^{-1}$ cone $^{-1}$ ) from a medium level of 6.3 (for both opsins) to 8.85 and 11.4 (bright) and 1.26 and 3.79 (dark) for Mand S-opsins, respectively. Stimulator intensity was measured at the level of the recording chamber using a calibrated photometer $(200-1100 \mathrm{~nm}$; Model 842-PE, Newport) set to the respective center wavelength of the LED filters. Cone photoisomerization rates were calculated using the relative sensitivities of the mouse cone opsins at the LED filter wavelengths via an opsin-template (Stockman and Sharpe, 2000) fitted to the peak sensitivities (360 and $511 \mathrm{~nm}$ ) (Jacobs et al., 1991) and assuming a cone's light collection area of $0.2 \mu \mathrm{m}^{2}$ (Nikonov et al., 2006). The stimuli always covered the whole retinal slice (full field). For both protocols, the slices were kept at the background (protocol 1) or the medium (protocol 2) intensity level for $1 \mathrm{~min}$ after the laser-scanning started before flashes were presented.

Imaging of pharmacologically evoked calcium changes by confocal laser scanning microscopy. Retinal slices were placed in a recording chamber perfused constantly with temperate $\left(\sim 36^{\circ} \mathrm{C}\right)$ carboxygenated ACSF. The microscope used was an Eclipse FN1microscope (Nikon) equipped with a diode laser (Radius 405-25, Radius Laser System; Coherent) that allowed to excite the fluorescence donor (eCFP) of the TN-XL indicator (at $405 \mathrm{~nm}$ ). A $40 \times$ water-immersion objective (Fluor, $40 \times / 0.80 \mathrm{w}$; Nikon) was used to acquire images $(256 \times 256$ pixels, for time-lapsed recordings every $5 \mathrm{~s}$ ) at the emission wavelengths of eCFP (469 BP 35; AHF) and citrine, the fluorescence acceptor (535 BP 30, AHF). Control images were recorded for at least $2 \mathrm{~min}$ before drug application, for which a focal perfusion system (tip diameter of $100 \mu \mathrm{m} ; \mathrm{VC}^{3} 4$ System, ALA Scientific Instrument) was used. Data analysis was done offline (see Data analysis, below).

Pharmacology. For stock solutions, all drugs were dissolved in water or DMSO, according to the vendor's instructions. Before each experiment, drugs were freshly prepared from stock solutions in carboxygenated ACSF. The final concentrations were as follows: $200 \mu \mathrm{M}$ zaprinast, 20 to $200 \mu \mathrm{M}$ $\mathrm{S}$-nitroso- $N$-acetyl-DL-penicillamine (SNAP), $100 \mu \mathrm{M} 2$-(4-carboxyphenyl)4,4,5,5-tetramethylimidazoline-1-oxyl-3-oxide (cPTIO), $50 \mathrm{~mm}$ caffeine, $100 \mu \mathrm{M} 1 \mathrm{H}-[1,2,4]$ oxadiazolo[4,3-a] quinoxalin-1-one (ODQ), $100 \mathrm{~mm}$ $\mathrm{KCl}$ (all others from Sigma-Aldrich), and 50-500 $\mu \mathrm{M}$ 8-(4-chlorophenylthio)guanosine- $3^{\prime}, 5^{\prime}$-cyclic monophosphate (8-pCPT-cGMP; BioLog). Caffeine, $\mathrm{KCl}$, and 8-pCPT-cGMP $(500 \mu \mathrm{M})$ were used in the confocal imaging experiments and puffed using a focal perfusion system $\left(\mathrm{VC}^{3} 4\right.$ System with 100- $\mu \mathrm{m}$-diameter tip manifold; ALA Scientific Instrument). Zaprinast, 8-pCPT-cGMP (50 $\mu \mathrm{M})$, SNAP, ODQ, and cPTIO were applied with the bathing solution during the $2 \mathrm{P}$ imaging experiments (with light stimulation). For statistical analysis, we used only light response data for which the respective drug was washed-in or washed-out for at least $20 \mathrm{~min}$.

Data analysis. For analysis of the pharmacological (puff) data, the EZ $\mathrm{C} 1$ confocal imaging software (Nikon) of the confocal microscope was used. For analyzing light response data, ImageJ (http://rsb.info.nih.gov/ ij/) and custom-written scripts for Igor Pro software (Wavemetrics) were used. ROIs were positioned on the cone pedicles and, in case of the puff data, also on the cone IS and soma. Background fluorescence was subtracted and the ratio $\left(R=F_{\mathrm{A}} / F_{\mathrm{D}}\right)$ between the signal of the fluorescence donor $\left(F_{\mathrm{D}}\right)$ eCFP and the fluorescence acceptor $\left(F_{\mathrm{A}}\right)$ citrine was calculated. An increase in $R$ (or $\Delta R / R$ ) represents an increase in intracellular calcium concentration $\left(\left[\mathrm{Ca}^{2+}\right]\right)$. Because we focused on relative and not absolute $\left[\mathrm{Ca}^{2+}\right]$ levels, we refrained from calibrating the setup and give the fluorescence ratio $R$ as a measure of $\left[\mathrm{Ca}^{2+}\right]$ level.

To quantify light-evoked $\mathrm{Ca}^{2+}$ changes in cones, we determined the following parameters: preresponse baseline ratio $\left(R_{\text {base }}\right)$, peak amplitude $(\Delta R)$, and area $\left(R_{\mathrm{A}}\right.$, the complete area under the curve). To quantify response rise and decay, we determined the time points where the traces reached $20 \%$ and $80 \%$ of $\Delta R$ (for both light onset and offset) from sigmoid fits of the $\mathrm{Ca}^{2+}$ response traces and calculated the differences, $t_{\text {rise }}$ and $t_{\text {decay }}$ (see Fig. $4 D$ ). We used a sigmoid instead of an exponential function because the former fitted the traces more reliably without adjusting the fit range manually for every cell. Note that "rise" refers to the initial drop in $\left[\mathrm{Ca}^{2+}\right]$ at light onset, whereas "decay" refers to the increase in $\left[\mathrm{Ca}^{2+}\right]$ at light offset. The effects of the drugs onto the different response parameters were statistically evaluated using the Wilcoxon's rank test.

\section{Results}

\section{$\mathrm{M}$ - and S-cones express the $\mathrm{Ca}^{2+}$ biosensor in the}

HR2.1:TN-XL mouse line

To target a calcium biosensor to mouse cones, we designed a construct that drives the expression of the TN-XL Ca ${ }^{2+}$ biosensor under the control of the human red opsin promoter HR2.1 (Wang et al., 1992). Using this construct, we generated a trans- 
genic line that stably transmits the transgene at a copy number of $\sim 10-15$ per haploid genome. To characterize the expression of TN-XL in cones and the distribution of TN-XL-positive cones across the retina, vertical sections and whole mounts of HR2.1:TN-XL retinas were double-labeled with antibodies against GFP to amplify TN-XL fluorescence and against M- or S-opsin (Fig. 1). We found that TN-XL is present throughout the cone with the exception of the OS (Fig. $1 A-C$ ). TN-XL immunolabeling of the cone population appeared to be complete, with some variations in expression level across the retina. Biosensor expression remained stable until at least 8 months of age (data not shown). Mice possess a dorsoventral opsin coexpression gradient, with $\mathrm{M}$-cones dominating the dorsal and M/S double-expressing cones dominating the ventral retina (Szél et al., 1992). This gradient is also present in the HR2.1:TN-XL mouse line, as shown by S-opsin labeling of whole-mounted retina (Fig. 1D). Despite this opsin coexpression gradient, cones that exclusively express S-opsin ("true" S-cones) are evenly distributed across the whole mouse retina (Haverkamp et al., 2005). Hence, to test whether TN-XL is also expressed by true S-cones, we also used dorsal vertical sections, where opsin coexpression is low (cf. Fig. $1 E, G$ with Fig. $1 F, H$ ). We found indeed that the rare S-opsinexpressing cones in dorsal retina are TN-XL positive (Fig. 1G, inset), suggesting that the HR2.1 promoter drives TN-XL expression in all cone types of the mouse.

Photoreceptor function is unaffected by TN-XL expression

In transgenic animals, the random insertion of transgene(s) may disturb endogenous gene functions. Additionally, the troponin $\mathrm{C}$ $\mathrm{Ca}^{2+}$-binding moiety of TN-XL (Mank et al., 2006) may alter the intrinsic cone $\mathrm{Ca}^{2+}$ buffering capacity and thereby affect $\mathrm{Ca}^{2+}$ signal spread and neurotransmitter release to postsynaptic neurons. To ascertain normal photoreceptor function in HR2.1:TN$X L$, we recorded scotopic and photopic ERGs from 1-month-old transgenic and wild-type mice. To assess cone function and synaptic transmission, we analyzed the photopic single flash b-wave, which is evoked by downstream ON-cone bipolar cells. The b-wave recorded from HR2.1:TN-XL mice was not significantly different from that in wild-type animals (Fig. 2A-C; for statistics, see legend), indicating normal $\mathrm{ON}$-cone bipolar cell function. To assess OFF-cone bipolar cell function, we applied a flicker stimulus protocol (see Materials and Methods, above) (Marmor et al., 2004), for which it was shown that responses at frequencies of $\geq 18 \mathrm{~Hz}$ are dominated by OFF cone bipolar cell activity (Krishna et al., 2002). At these frequencies, there was no significant difference in flicker response between wild-type and HR2.1:TN-XL mice (Fig. $2 D, E$ ). This suggests that cone function as well as transmission from cones to bipolar cells is not disturbed by expression of TN-XL. Moreover, under scotopic conditions, the function of rods (indicated by the a-wave) and rod bipolar cells (indicated by the b-wave) is not significantly different between transgenic and wild-type (Fig. $2 F-H$ ). In conclusion, our ERG data indicated that neither transgene insertion nor expression levels of TN-XL in cones interfere with normal photoreceptor function in HR2.1:TN-XL mice. Additionally, ERG recordings from 3-month-old HR2.1:TN-XL mice and their littermates did not show significant differences (data not shown), suggesting that TN-XL expression has no progressive effects on photoreceptor function in the adult retina.

\section{Changes in $\left[\mathrm{Ca}^{2+}\right]$ are largely restricted to cone terminals}

To show that TN-XL allows monitoring changes in cone cytosolic $\mathrm{Ca}^{2+}$ and to investigate the subcellular distribution of these changes, we performed $\mathrm{Ca}^{2+}$ imaging on light-adapted retinal slices while puffing different drugs onto the retinal slice (Fig. $3 A, B)$. Pharmacologically induced $\mathrm{Ca}^{2+}$ changes were largely restricted to the cone terminals, with no or only small responses in the soma or the IS (Fig. 3B2), pointing at a high degree of compartmentalization.

In light-adapted retina, cone membrane potential is hyperpolarized, such that voltage-gated $\mathrm{Ca}^{2+}$ channels (VGCCs) are closed and resting $\left[\mathrm{Ca}^{2+}\right.$ ] is low in the terminal (Choi et al., 2005; Krizaj, 2005). Depolarization of cones with high extracellular $\mathrm{KCl}$ (Fig. $\left.3 B_{2}, B_{3}\right)$ evoked large increases in fluorescence ratio $(R=$ $\left.F_{\mathrm{A}} / F_{\mathrm{D}}\right)$ and therefore in $\left[\mathrm{Ca}^{2+}\right](\Delta R / R=0.94 \pm 0.29, n=45$ of 48 
A

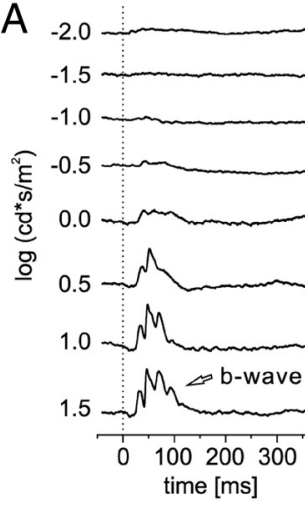

F

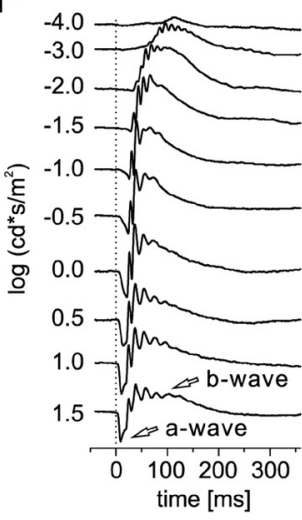

B

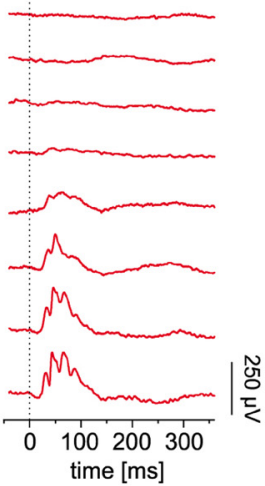

G

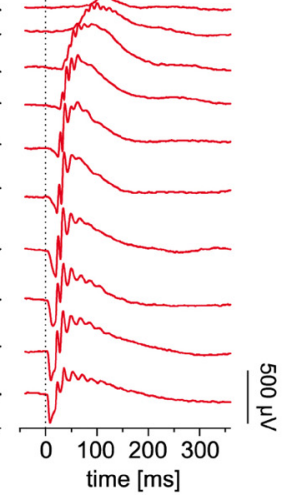

G
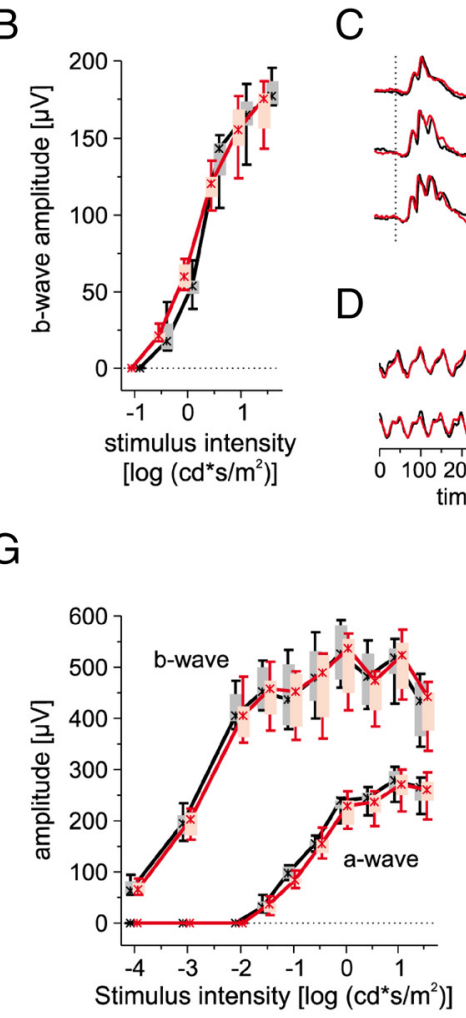

C

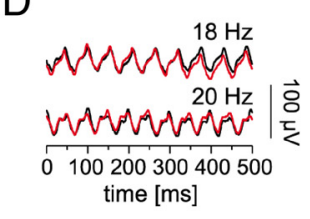

E

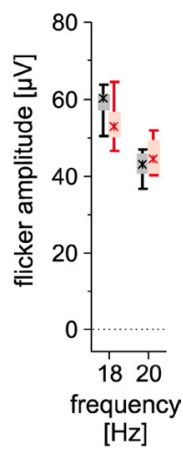

$\mathrm{H}$

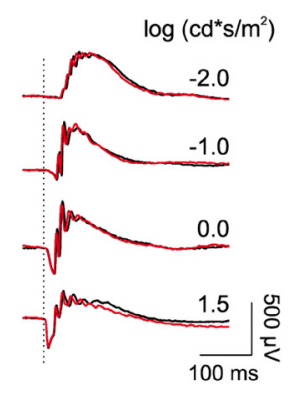

Figure 2. ERG analysis of HR2.1:TN-XL mice versus wt mice. $A$, Representative photopic single-flash ERGs in 1-month-old HR2.1:TN-XL (red) and wt (black) mice under a static background light $\left(30 \mathrm{~cd} / \mathrm{m}^{2}\right)$. The arrow indicates the b-wave. B, Box-and-whisker plot showing photopic single-flash b-wave amplitudes in wt (black) and HR2.1:TN-XL (red) mice. Boxes indicate the 25\% and 75\% quantile range, whiskers indicate the $5 \%$ and $95 \%$ quantiles, and the asterisks indicate the median of the data. The amplitude differences were not statistically significant at any intensity $(p=0.13$ to $\left.0.67 \mathrm{for}-0.5 \mathrm{to} 1.5 \mathrm{~cd} \cdot \mathrm{s} / \mathrm{m}^{2}\right)$.C, Overlay of the response traces of wt (black) and HR2.1:TN-XL (red) mice from A.D, Representative flicker ERG response traces at 18 and $20 \mathrm{~Hz}$ under dark-adapted condition in wt (black) and HR2.1:TN-XL (red) mice. E, BoX-and-whisker plot showing flicker response amplitudes of wt (black) and HR2.1:TN-XL (red) mice ( $p=0.31$ for $18 \mathrm{~Hz}, p=0.39$ for $20 \mathrm{~Hz}$ ). $\boldsymbol{F}$, Representative scotopic single flash ERGs in wt (black) and HR2.1:TN-XL (red) mice. Arrows indicate the a- and b-waves. G, Box-and-whisker plot of scotopic single-flash a- and b-wave amplitudes in wt (black) and HR2.1:TN-XL (red) mice. The amplitude differences were not statistically significant at any intensity $\left(p=0.093-1.00\right.$ for $-1.5-1.5 \mathrm{~cd} \cdot \mathrm{s} / \mathrm{m}^{2}$ for the a-wave, $p=0.39-0.94$ for $-4-1.5 \mathrm{~cd} \cdot \mathrm{s} / \mathrm{m}^{2}$ for the b-wave). $\boldsymbol{H}$, Overlay of the response traces of wt (black) and HR2.1:TN-XL (red) mice from $\boldsymbol{F}$.

cone terminals from 4 experiments) in cone terminals, reflecting $\mathrm{Ca}^{2+}$ influx through VGCCs, likely of the L-type (Taylor and Morgans, 1998). The absence of a substantial $\mathrm{Ca}^{2+}$ response in IS and soma $(\Delta R / R=0.11 \pm 0.10, n=48$ cells $)$ is consistent with the absence of VGCCs in these compartments (Morgans et al., 2005). We then applied caffeine, a ryanodine receptor agonist, to induce $\mathrm{Ca}^{2+}$ release from the endoplasmic reticulum (ER) (Blinks et al., 1972). Caffeine puffs (Fig. $3 B_{3}$ ) increased $\left[\mathrm{Ca}^{2+}\right]$ in cone terminals $(\Delta R / R=0.77 \pm 0.35, n=38$ of 40 terminals from 3 experiments) but not in the soma or the IS $(\Delta R / R=0.08 \pm$ $0.08, n=40$ cells), suggesting that $\mathrm{Ca}^{2+}$-induced $\mathrm{Ca}^{2+}$ release (CICR) from the ER is mainly involved in $\mathrm{Ca}^{2+}$ regulation in the terminal. As TN-XL is not expressed in the cone OS, we were not able to directly monitor $\mathrm{Ca}^{2+}$ in this compartment. To show that OS were intact, we applied the membrane-permeable cGMP analog 8-pCPT-cGMP, which causes opening of cyclic nucleotidegated $(\mathrm{CNG})$ channels and depolarization of cones. 8-pCPTcGMP induced an increase of $\left[\mathrm{Ca}^{2+}\right]$ in the majority of terminals $(\Delta R / R=0.73 \pm 0.32, n=31$ of 38 terminals from 3 experiments; Fig. $\left.3 B_{3}\right)$, but not in soma and IS $(\Delta R / R=0.07 \pm 0.07, n=38)$. This indicated that CNG channel-mediated $\mathrm{Ca}^{2+}$ influx into OS (Wei et al., 1998) does not directly contribute, e.g., by diffusion, to the $\left[\mathrm{Ca}^{2+}\right]$ rise in terminals.

Together, these results show that TN-XL expression in cones allows detection of drug-evoked changes in $\left[\mathrm{Ca}^{2+}\right]$ via different pathways. They also suggest that regulation of $\left[\mathrm{Ca}^{2+}\right]$ in cone terminals differs from that in soma and IS and is highly compartmentalized in mammalian cone photoreceptors.

\section{Expression of TN-XL allows recording of light-evoked $\mathrm{Ca}^{2+}$ responses in cone terminals}

To evaluate cone $\mathrm{Ca}^{2+}$ dynamics under more physiological conditions, we recorded light-evoked $\mathrm{Ca}^{2+}$ responses, focusing on cone terminals (Fig. 3C), using slices from dark-adapted HR2.1: $T N-X L$ retina and 2P microscopy (Denk et al., 1990). We restricted laser scanning to a narrow region covering cone terminals in the outer plexiform layer (OPL; Fig. $3 A, C_{1}$ ). The perpendicular orientation of the laser beam to the slice surface prevented direct laser illumination of the light-sensitive cone OS. This measure was crucial to avoid bleaching of photopigments by the excitation laser, because even $\sim 100 \mu \mathrm{m}$ away from the focal plane, $2 \mathrm{P}$ excitation of photopigments is the largest contributor to light responses evoked by the pulsed infrared scanning laser beam (here $\sim 860 \mathrm{~nm}$ ) used in $2 \mathrm{P}$ microscopy (Denk and Detwiler, 1999; Euler et al., 2009).

When presenting light flashes to the slice, we detected decreases in fluorescence ratio $(R)$ in individual cone terminals at single trial level (Fig. $3 \mathrm{C}$ ), indicating decreases in $\left[\mathrm{Ca}^{2+}\right]$, as lightevoked hyperpolarization leads to closure of VGCCs at the cone terminal (Choi et al., 2005). Laser scanning affected both resting 
A

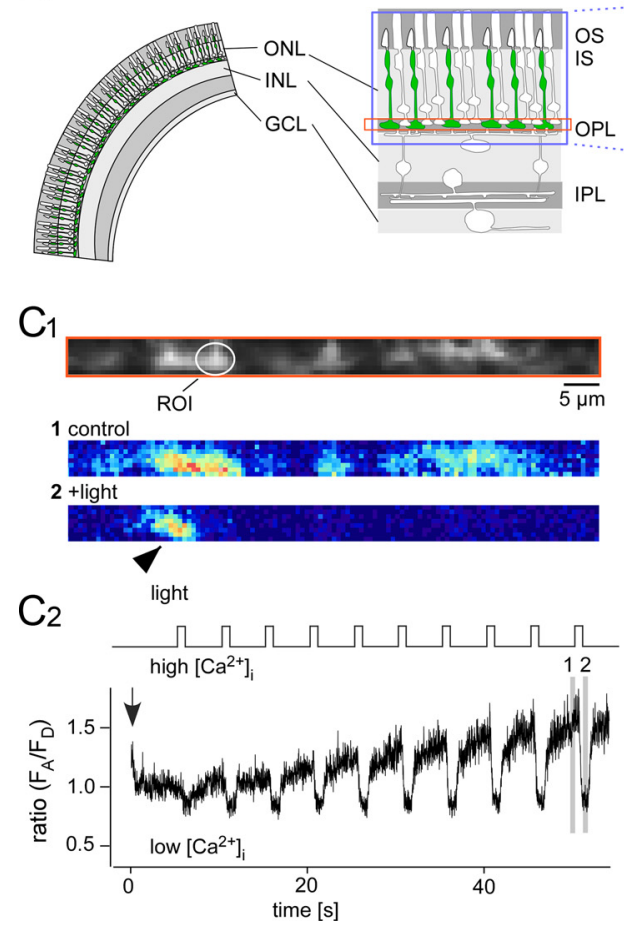

$\mathrm{B}_{1}$

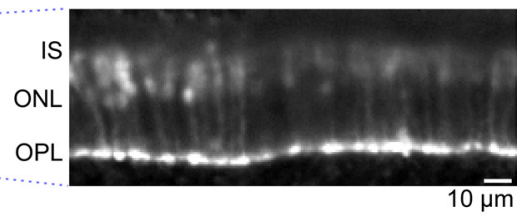

$\mathrm{B}_{2}$

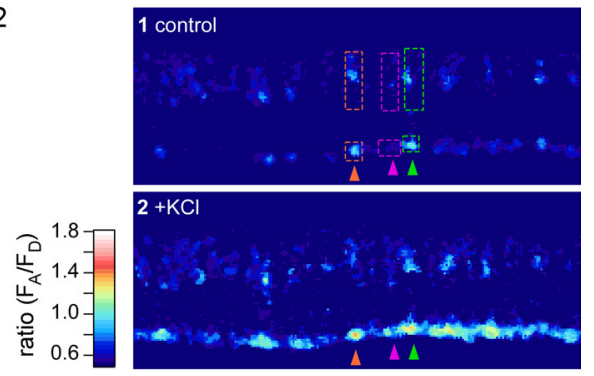

$\mathrm{B}_{3}$

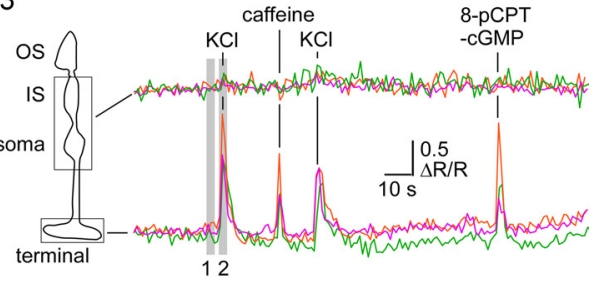

Figure 3. $\quad \mathrm{Ca}^{2+}$ responses of cone photoreceptors in the HR2.1:TN-XL mouse. A, Schematic drawing of retinal slice with TN-XL-expressing cones (green). B, Slice from HR2.1:TN-XL mouse imaged using a confocal microscope $\left(\boldsymbol{B}_{1}\right)$ while puffing drugs. Three TN-XL-positive cones with ROls located on IS and soma as well as on the respective terminals before ( $\boldsymbol{B}_{2}$, top) and during a puff of 100 mм KCl ( $\boldsymbol{B}_{2}$, bottom) are shown (pseudocolored images represent ratios $R=F_{A} / F_{D}$, reflecting the intracellular $\left[\mathrm{Ca}^{2+}\right]$ level, and are averages of $n=5$ frames $)$. $\mathrm{Ca}^{2+}$ signals $\left(\boldsymbol{B}_{3}\right.$; as fractional change of fluorescence ratio, $\Delta R / R$; from ROls in $\boldsymbol{B}_{\mathbf{2}}$ ) measured in IS + soma (top trace) and terminals (bottom trace) in response to puffs of $100 \mathrm{~mm} \mathrm{KCI}(1 \mathrm{~s}), 50 \mathrm{~mm}$ caffeine, and $500 \mu \mathrm{m}$ 8-pPCPT-cGMP (both $5 \mathrm{~s}$ ). Gray bars indicate when frames for images in $\boldsymbol{B 2}$ were taken. $\boldsymbol{C}$, Light-evoked $\mathrm{Ca}^{2+}$ responses recorded from cone terminals; the imaged area covered the $0 \mathrm{PL}$, as indicated by the orange box in $\boldsymbol{A}$. Ratio images $\left(\boldsymbol{C}_{\boldsymbol{1}}\right.$, averages of $n=20$ frames; for color bar, see $\left.\boldsymbol{B}_{\mathbf{2}}\right)$ reflect $\left[\mathrm{Ca}^{2+}\right]$ levels before (middle) and during (bottom) a flash of light. Multiple light responses $\left(\boldsymbol{C}_{\mathbf{2}}\right.$, as ratio $\left.R=F_{A} / F_{D}\right)$ recorded from an ROI (circle) placed on an exemplary cone terminal (in $\boldsymbol{C}_{\boldsymbol{1}}$ ). Note single nonresponsive cone terminal (arrowhead in $\boldsymbol{C}_{\boldsymbol{1}}$ ). Laser scanning was started (arrow) briefly before the light

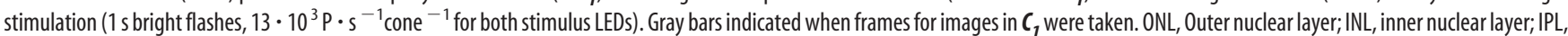
inner plexiform layer; GCL, ganglion cell layer.

$\left[\mathrm{Ca}^{2+}\right]$ level and light responses. However, the scanned cones adapted to this background illumination within 30-60 s (Fig. $3 C_{2}$ ), such that after this time period stable light responses could be recorded from sets of cone terminals (Fig. 4). We did not explore whether the laser effect was due to scattered laser light or evoked TN-XL fluorescence or a combination of both (for discussion, see Denk and Detwiler, 1999; Euler et al., 2009).

It is known that physiological $\left[\mathrm{Ca}^{2+}\right]$ levels in cones range from $50 \mathrm{~nm}$ to $2 \mu \mathrm{M}$ (Szikra and Krizaj, 2006). Because of its relatively high $K_{\mathrm{D}}(0.7-2.2 \mu \mathrm{M})$ (Hendel et al., 2008), it is unlikely that TN-XL is saturated by the $\left[\mathrm{Ca}^{2+}\right]$ levels reported for cones. This is also supported by the finding that even GCaMP2 with a much lower $K_{\mathrm{D}}$ is far from saturated in bipolar cell terminals, which likely exhibit a larger dynamic $\mathrm{Ca}^{2+}$ range than cones (Dreosti et al., 2009). During the light response, in most terminals, $\left[\mathrm{Ca}^{2+}\right]$ decreased to a consistent level (Fig. $4 \mathrm{~B}$ ). This may be explained by saturating light responses, but the possibility cannot be excluded that TN-XL reaches the end of its dynamic range and fails to report $\left[\mathrm{Ca}^{2+}\right]$ as low as $50 \mathrm{nM}$. Nevertheless, the fact that we observed responses with different polarities (Fig. 4A) suggests that the dynamic range of TN-XL is sufficient to largely cover light-driven $\left[\mathrm{Ca}^{2+}\right]$ dynamics in mouse cones. While there was some noise-related trial-to-trial variability, the light responses were highly reproducible over many trials (Fig. $4 C_{1}, C_{2}$ ), with stable signal-to-noise ratios (Fig. $4 C_{3}$ ). With the exception of very few animals with low expression, we did not observe any relevant bleaching. This is illustrated by the fact that noise on response traces, a telltale sign for bleaching in ratiometric measurements, did not substantially change even for prolonged measurements over the course of $>1$ h with up to $\sim 120$ trials (Fig. $4 C_{3}$; Figs. $5 A, 6 A, 7 A$, traces).

To quantify light-evoked $\mathrm{Ca}^{2+}$ responses in cone terminals, we determined five response parameters (Fig. $4 D$ ): baseline $\left[\mathrm{Ca}^{2+}\right]$ level $\left(R_{\text {base }}\right)$, response size [peak amplitude $(\Delta R)$ and area $\left.\left(R_{\mathrm{A}}\right)\right]$ and time course [rise time $\left(t_{\text {rise }}\right)$ and decay time $\left(t_{\text {decay }}\right)$; for details, see Materials and Methods, above). While baseline $\left[\mathrm{Ca}^{2+}\right]$ levels were rather constant $\left(R_{\text {base }}=0.93 \pm 0.14\right)$, response amplitudes to steps of light varied among analyzed cones $\left(\Delta R=-0.20 \pm 0.13, R_{\mathrm{A}}=-0.23 \pm 0.14 ; n=58\right)$. The response rise at light-onset (decrease in $\left[\mathrm{Ca}^{2+}\right] ; t_{\text {rise }}=219 \pm 131 \mathrm{~ms}$ ) was significantly shorter than the response decay at light-offset (increase in $\left[\mathrm{Ca}^{2+}\right] ; t_{\text {decay }}=550 \pm 504 \mathrm{~ms}$ ). This may indicate that extrusion of $\mathrm{Ca}^{2+}$ from cone terminals at light-onset was faster than $\mathrm{Ca}^{2+}$ influx through VGCCs at light off-set, possibly reflecting the fast clearance rate of the plasma membrane $\mathrm{Ca}^{2+}$ ATPase (Caride et al., 2001). Nevertheless, this temporal difference may also be at least partially due to the TN-XL Ca ${ }^{2+}$ binding dynamics, which is unusual in that $\mathrm{Ca}^{2+}$ unbinding from the TN-XL component troponin $\mathrm{C}\left(\tau_{\text {decay }} \approx 0.2 \mathrm{~s}\right)$ is faster than $\mathrm{Ca}^{2+}$ binding $\left(\tau_{\text {rise }} \approx 0.6 \mathrm{~s}\right)$ (Hendel et al., 2008). Therefore, the biosensor kinetic is expected to slow the observed response decay, suggesting that the actual difference between $t_{\text {rise }}$ and $t_{\text {decay }}$ is likely to be smaller. In $22(10 \%)$ of 216 light-responsive cones, we observed an "overshoot" component at light-offset (Fig. $4 E_{1}$ ), which we 
A
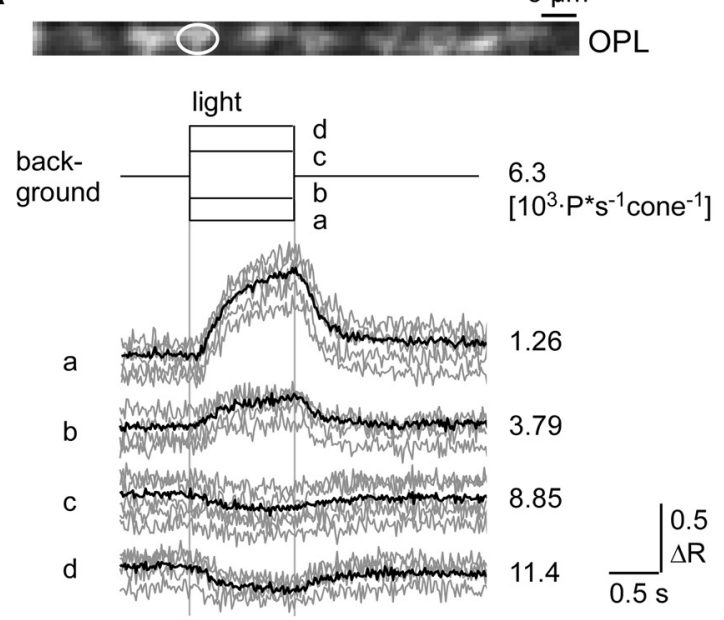

$\mathrm{C}_{1}$

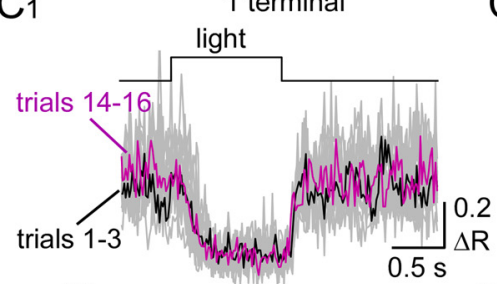

C2 19 terminals

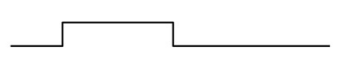

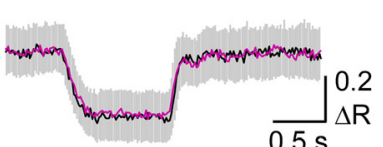

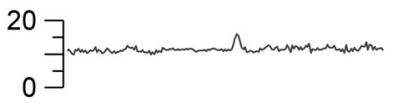

D

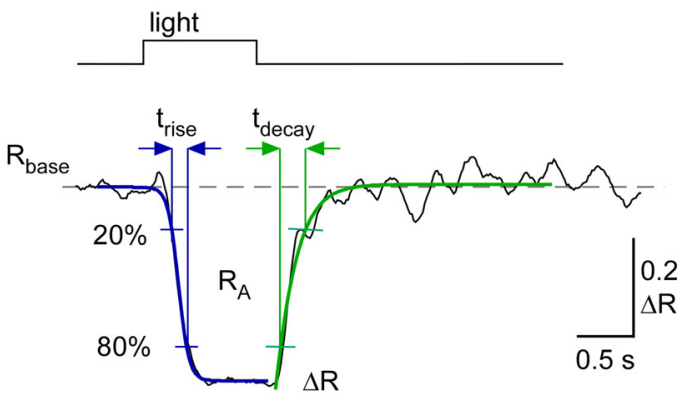

B
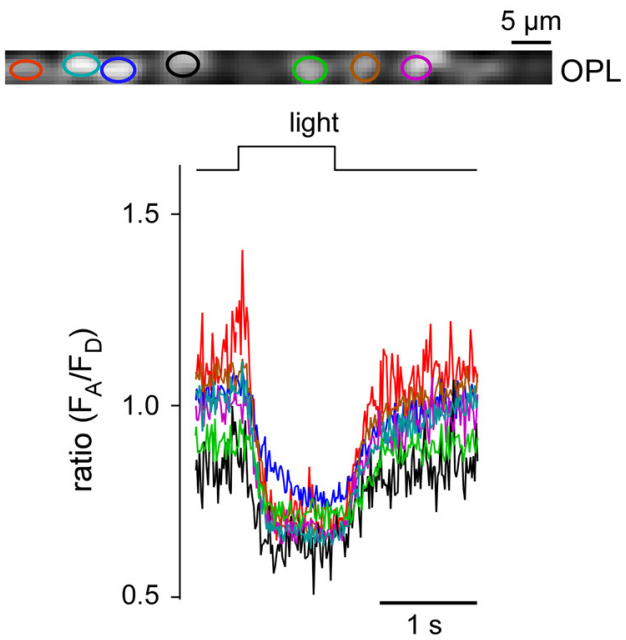

$\mathrm{C}_{3}$

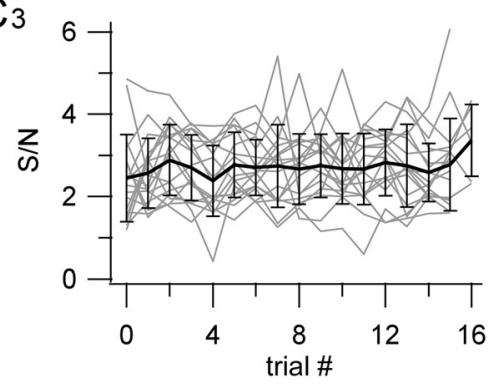

$E_{2}$
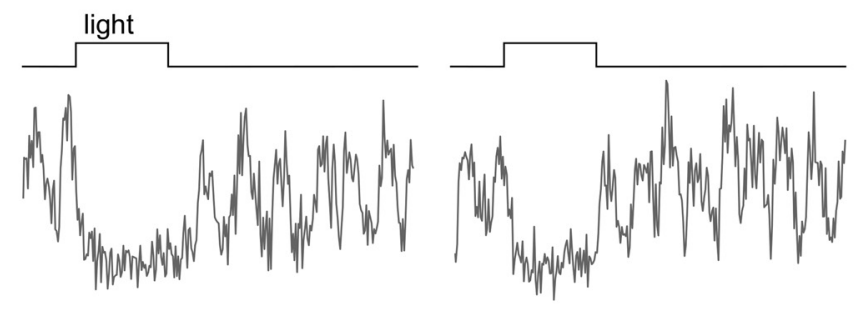

$E_{1}$

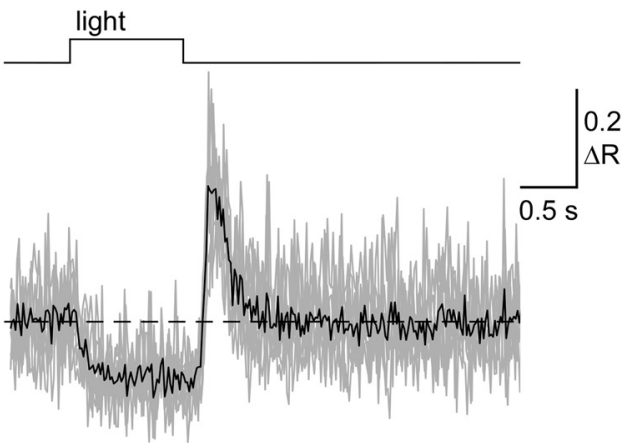

E2

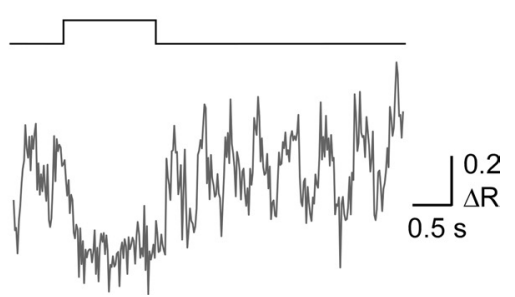

Figure 4. Quantification of light-evoked $\mathrm{Ca}^{2+}$ responses in cone terminals. $A, \mathrm{Ca}^{2+}$ responses as change in ratio $(\Delta R)$ evoked by darker-than-background (conditions a, b) and brighter-than-background (conditions $c$, d) flashes of different intensities in a single cone terminal (background and flash isomerization rates next to traces; averages of $n=10$ trials in black, single trials in gray). $\boldsymbol{B}$, Light-evoked $\mathrm{Ca}^{2+}$ responses from seven cone terminals, as marked by color-coded ROls (averaged traces from $n=10$ trials each). $\boldsymbol{C}$, Single-trial light responses ( $\boldsymbol{C}_{1}$, gray top traces, $n=18$ trials) of individual cone terminal, with averages of first (1-3, black) and last (14-16, magenta) three trials overlaid, and SD as function of time plotted below. Averages of first (1-3, black) and last (14-16, magenta) three trials pooled from 18 terminals in three experiments $\left(\boldsymbol{C}_{2}\right.$, with SD in gray) and SD over all $n=310$ trials as a function of time below. Signal-to-noise ratio $(\mathrm{S} / \mathrm{N})$ as function of trial $\left[\boldsymbol{C}_{3}\right.$; traces for $n=19$ terminals from $\boldsymbol{C}_{2}$ in gray, average with SD in black; signal-to-noise ratio defined as ratio of peak amplitude $(\Delta R$; see also $\boldsymbol{D})$ and $S D$ measured in $0.5 \mathrm{~s}$ time window before light stimulus]. $\boldsymbol{D}$, For quantification, five parameters were determined from the responses (black): baseline ratio $\left(R_{\text {base }}\right)$, reflecting resting $\left[\mathrm{Ca}^{2+}\right]$; peak amplitude $(\Delta R)$ and area under the curve $\left(R_{\mathrm{A}}\right)$ as measures for response size; and rise $\left(t_{\text {rise }}\right)$ and decay $\left(t_{\text {decay }}\right)$ time, characterizing the time course, were determined from two sigmoid functions fitted to rise (blue) and decay (green) of the response (for details, see Materials and Methods). Examples for two less frequent response profiles: an overshoot at light-off (not quantified) was observed in some cones $\left(\boldsymbol{E}_{1}, n=9\right.$ trials, overlaid in gray); some responses displayed spike-like activity ( $\boldsymbol{E}_{2} ; 3$ exemplary single-trials). Only responses like those shown in $\boldsymbol{D}$ and $\boldsymbol{E}_{\boldsymbol{1}}$ were included in the statistical analysis. 
A
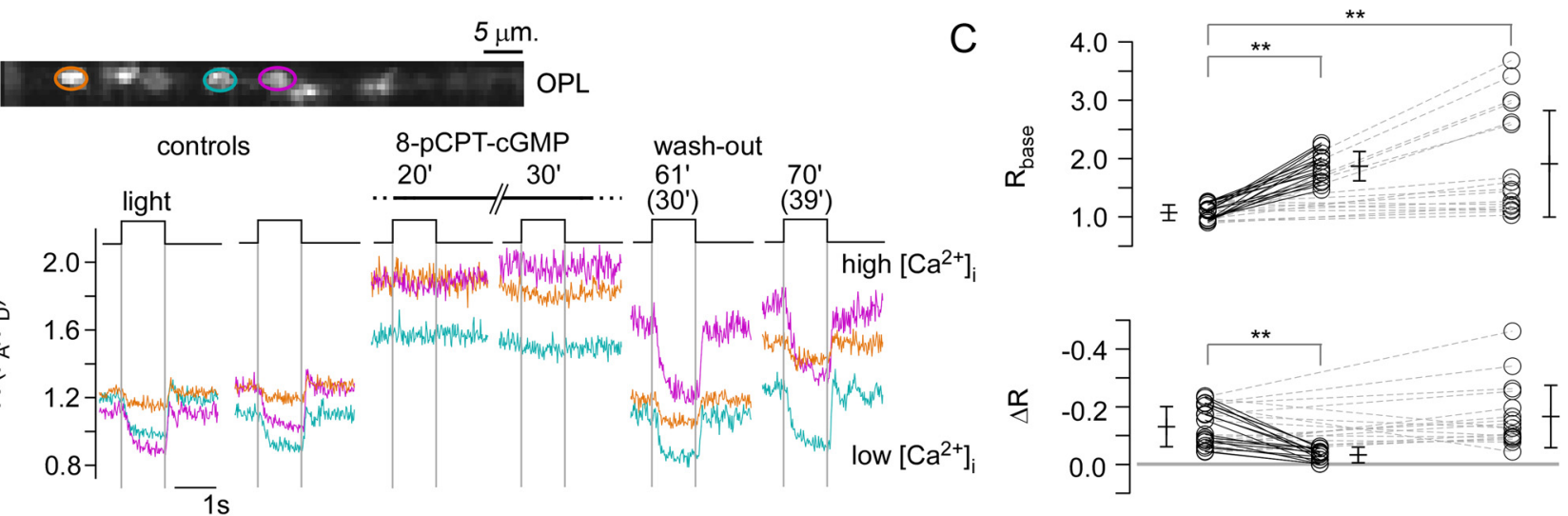

B
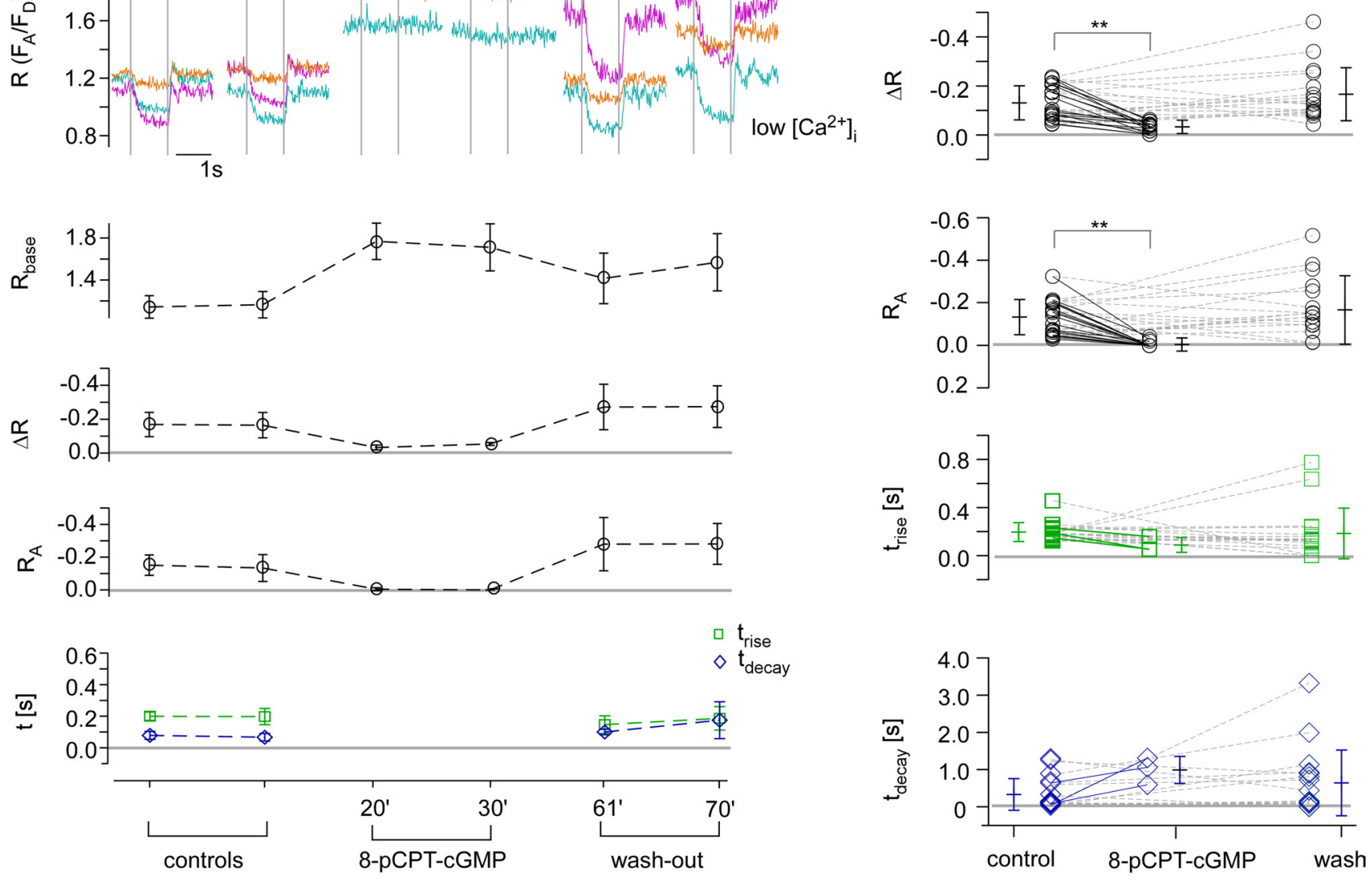

Figure 5. Effect of 8-pCPT-cGMP on the light-evoked $\mathrm{Ca}^{2+}$ response in cone terminals. $\boldsymbol{A}$, Light-evoked $\mathrm{Ca}^{2+}$ responses in three representative cone terminals (marked by color-coded ROls) before, during, and after wash-out of 8-pCPT-cGMP (50 $\mu \mathrm{m}$, bath application). Time points given from application start (in brackets: from beginning of wash-out). $\boldsymbol{B}, \mathrm{Quantification}$ of the responses of all seven cone terminals recorded in the experiment shown in $\boldsymbol{A}$. C, Summary of the 8-pCPT-cGMP effect on light-evoked Ca ${ }^{2+}$ responses for $n=17$ terminals (from 4 retinas), with each symbol representing a cone (averages $\pm S D$ are given next to each symbol column). For the timing parameters $\left(t_{\text {rise, }}, t_{\text {decay }}\right.$ ), values are only plotted for cones $(n=3)$, of which the response was not completely suppressed by 8-pCPT-cGMP (Wilcoxon signed test for paired samples, ${ }^{* *} p<0.01$; all others, not significant).

did not quantify. In 25 (12\%) of the light-responsive cones, we observed spontaneous spike-like events (Fig. $4 E_{2}$ ), which may be due to tissue damage, as they typically occurred in multiple cones of the same slice.

\section{Light-evoked $\mathrm{Ca}^{2+}$ responses allow detailed analysis of phototransduction}

Next, we combined light stimulation with pharmacological manipulation of the phototransduction cascade to evaluate the versatility of the TN-XL recorded $\mathrm{Ca}^{2+}$ signal in cone terminals. To directly increase CNG channel activity, we applied 8-pCPT-cGMP with the bath solution and measured its effect on light-evoked $\mathrm{Ca}^{2+}$ responses (Fig. 5). Since 8-pCPT-cGMP is $\sim 80$ times more potent at CNG channel activation than cGMP (Wei et al., 1998) and resistant to hydrolysis by phosphodiesterase 6 (PDE6) (Hurwitz et al., 1985), it clamps the channels in their opened state, leading to a tonic depolarization of cones and a strong $\mathrm{Ca}^{2+}$ influx to the terminal (Fig. $5 A, B)$. During application of 8 -pCPT-cGMP, the light-evoked $\left[\mathrm{Ca}^{2+}\right]$ changes were completely abolished in almost all cones. The wash-out was incomplete, since the light responses recovered but resting $\left[\mathrm{Ca}^{2+}\right]\left(R_{\text {base }}\right)$ remained higher than before application (Fig. $5 C$; for statistics, see Table 1 ).

Another way of influencing the open probability of CNG channels is to inhibit PDE6, which slows down cGMP hydrolysis in the OS (Sahaboglu et al., 2010) and, thus, promotes $\mathrm{Ca}^{2+}$ influx through CNG channels. To this end, we used the PDE6selective inhibitor zaprinast (Fig. 6) (Zhang et al., 2005), which induced a strong increase in resting $\left[\mathrm{Ca}^{2+}\right]\left(R_{\text {base }}\right)$ as well as a prolonged $t_{\text {rise }}$ and an increase in $\Delta R$ and $R_{\mathrm{A}}$ (Fig. 6A-C; for statistics, see Table 1). In contrast to the results with the cGMP analog, light responses remained intact in this experiment, indicating that PDE6 activity was only partially blocked by zaprinast, slowing down the phototransduction cascade. This is supported by our finding that zaprinast significantly increased $t_{\text {rise }}$ (but not $\left.t_{\text {decay }}\right)$, which can most likely be explained by the partially inhibited PDE6 not being able to bring down cGMP levels quickly enough, causing opened $\mathrm{CNG}$ channels to compete with $\mathrm{Ca}^{2+}$ extrusion mechanisms at the onset of the light response. As with 
A
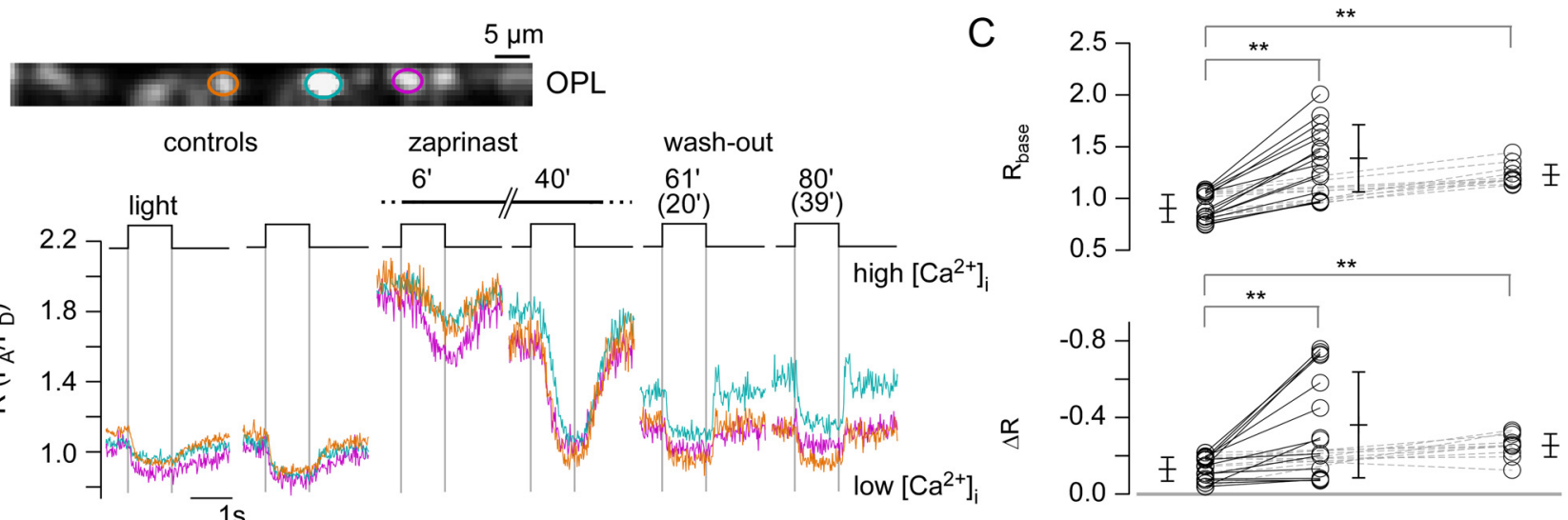

B
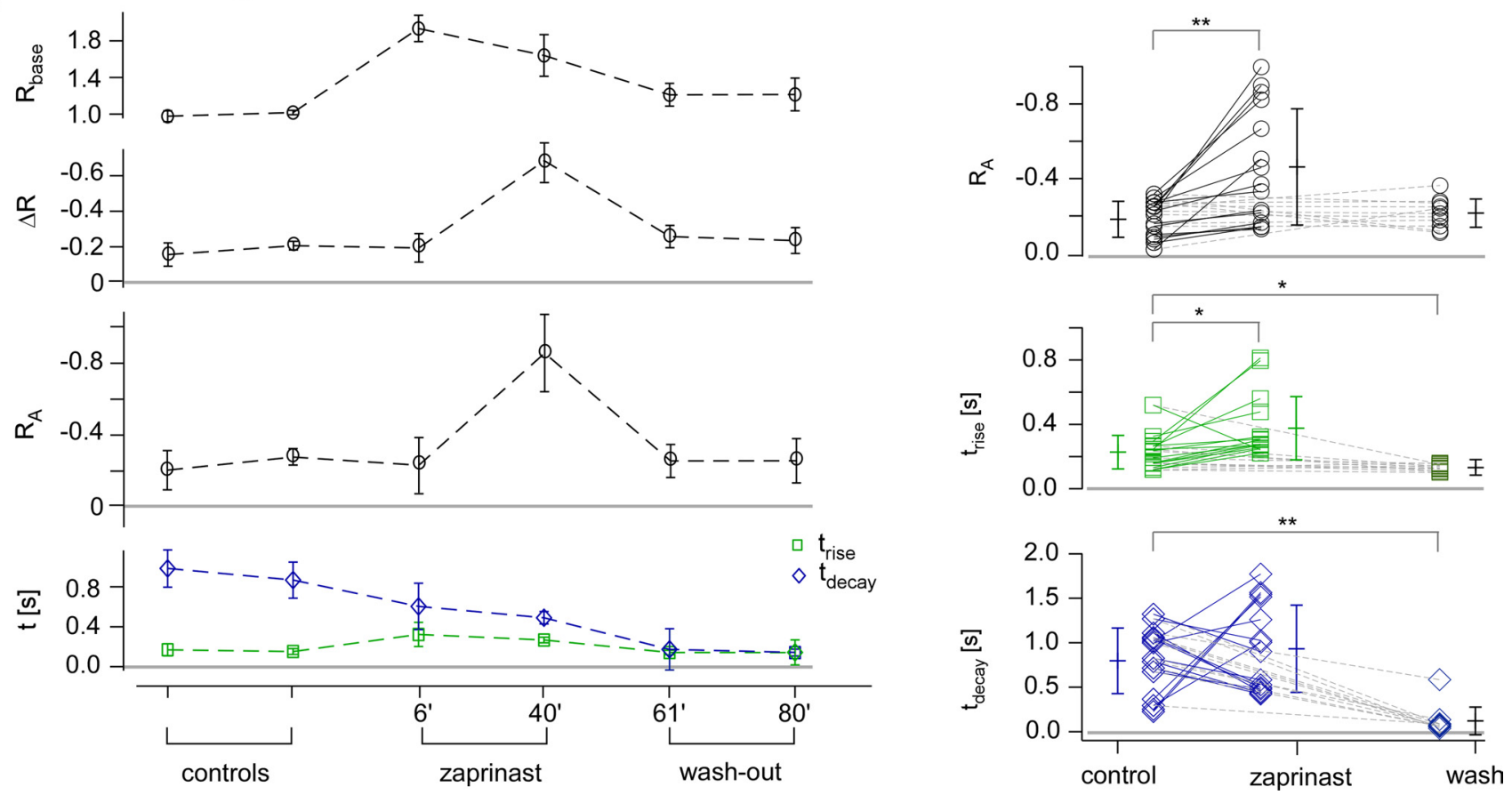

Figure 6. Effect of zaprinast on the light-evoked $\mathrm{Ca}^{2+}$ response in cone terminals. A, Light-evoked $\mathrm{Ca}^{2+}$ responses in three representative cone terminals (marked by color-coded ROIs) before, during, and after wash-out of zaprinast, a PDE6 inhibitor (200 $\mu \mathrm{m}$, bath application). B, Quantification of responses in all six cone terminals recorded in the experiment shown in $\boldsymbol{A}$. C, Summary of the zaprinast effect on light-evoked $\mathrm{Ca}^{2+}$ responses for $n=15$ terminals (from 3 retinas). For the timing parameters $\left(t_{\text {rise }} t_{\text {decay }}\right)$, values are only plotted for cones $(n=11)$ in which responses were not completely suppressed by zaprinast. Wilcoxon signed test for paired samples, ${ }^{* *} p<0.01,{ }^{*} p<0.05$; all others, not significant. See Figure. 5 for further experimental details.

the cGMP analog, wash-out appeared incomplete, since neither resting $\left[\mathrm{Ca}^{2+}\right]$ nor peak responses returned to their preapplication levels (Fig. 6C).

In conclusion, our results show that the HR2.1:TN-XL mouse allows to efficiently study different functional aspects of phototransduction in cones by monitoring light-driven $\mathrm{Ca}^{2+}$ responses in cone terminals.

\section{Nitric oxide decreases $\left[\mathrm{Ca}^{2+}\right]$ levels in cones through an sGC-independent pathway}

For amphibians it was proposed that NO influences photoreceptor synaptic output via the sGC-cGMP-mediated pathway (Kurenny et al., 1994; Rieke and Schwartz, 1994; Savchenko et al., 1997). While NO was shown to modulate phototransduction in mammalian cones (Sato and Ohtsuka, 2010; Vielma et al., 2010), at present it is unclear whether the effect is based on this very pathway. We therefore tested whether the HR2.1:TN-XL mouse allows detection of NO-mediated signaling in cones. To this end, we first used the NO donor SNAP at $200 \mu \mathrm{M}$, inspired by a recent
ERG study (Sato and Ohtsuka, 2010), and probed its effect on cone terminal $\mathrm{Ca}^{2+}$ signals (Fig. 7).

In the presence of $200 \mu \mathrm{M}$ SNAP, resting $\left[\mathrm{Ca}^{2+}\right]$ levels $\left(R_{\text {base }}\right)$ as well as $\Delta R$ and $R_{\mathrm{A}}$, were significantly decreased (Fig. 7, Table 1). These changes were irreversible (wash-out period: $30 \mathrm{~min}$ ). Lower concentrations of SNAP $(20-50 \mu \mathrm{M})$ had similar effects (data not shown). Over the course of the experiments, $t_{\text {decay }}$ decreased, possibly following a general trend (cf. Fig. 6C), and may therefore not be drug-related. To confirm that the decrease in $\left[\mathrm{Ca}^{2+}\right]$ level and response size were indeed NO-mediated, we used SNAP solution from which NO was gassed out (solution in an open vial overnight), which had no significant effect on light responses (data not shown). To examine the possibility of endogenous NO signaling, we applied the NO scavenger cPTIO. In one of four experiments, bath-application of cPTIO weakly increased both resting $\left[\mathrm{Ca}^{2+}\right]$ level and response size, whereas in the remaining three experiments, no significant effects were observed (data not shown). Using the diaphorase assay, we tested for endogenous NO production in mouse retina. NOS activity was 

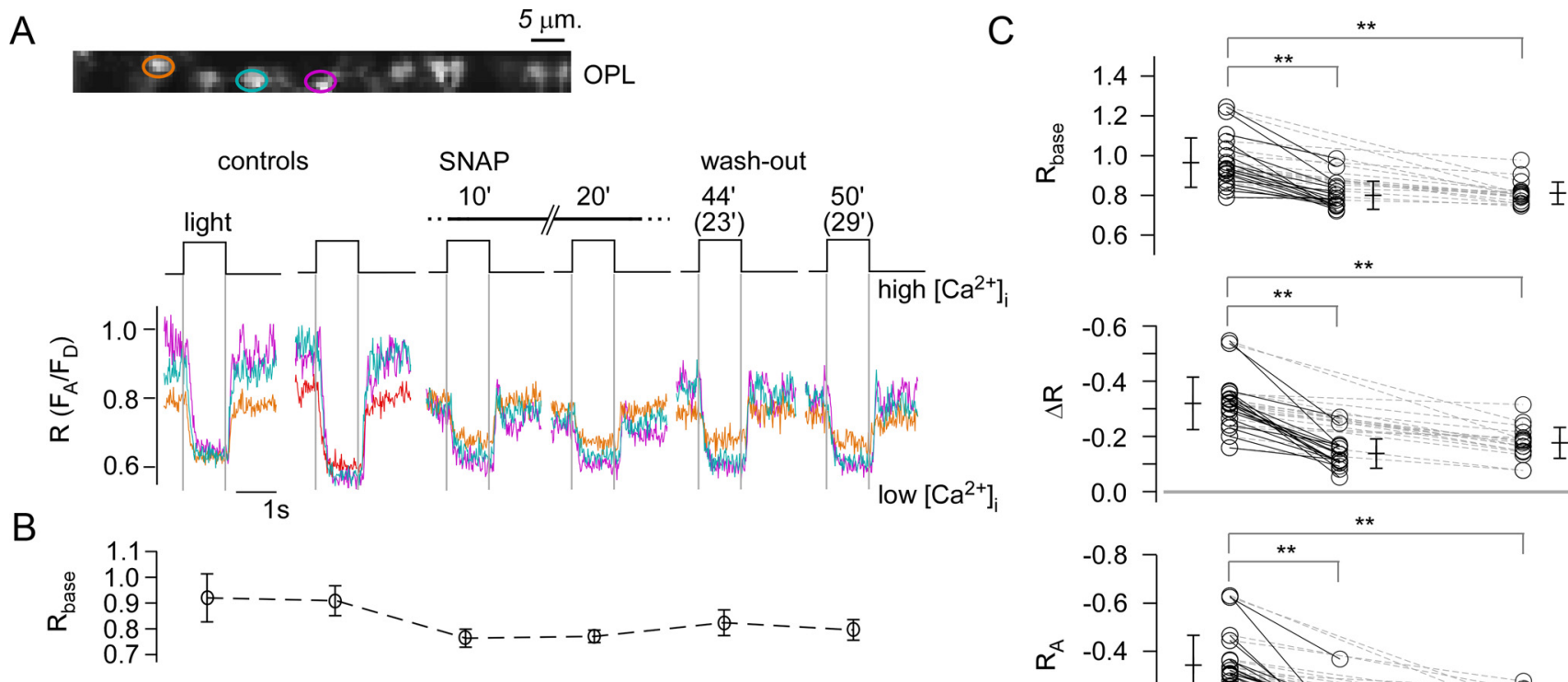

low $\left[\mathrm{Ca}^{2+}\right]_{\mathrm{i}}$
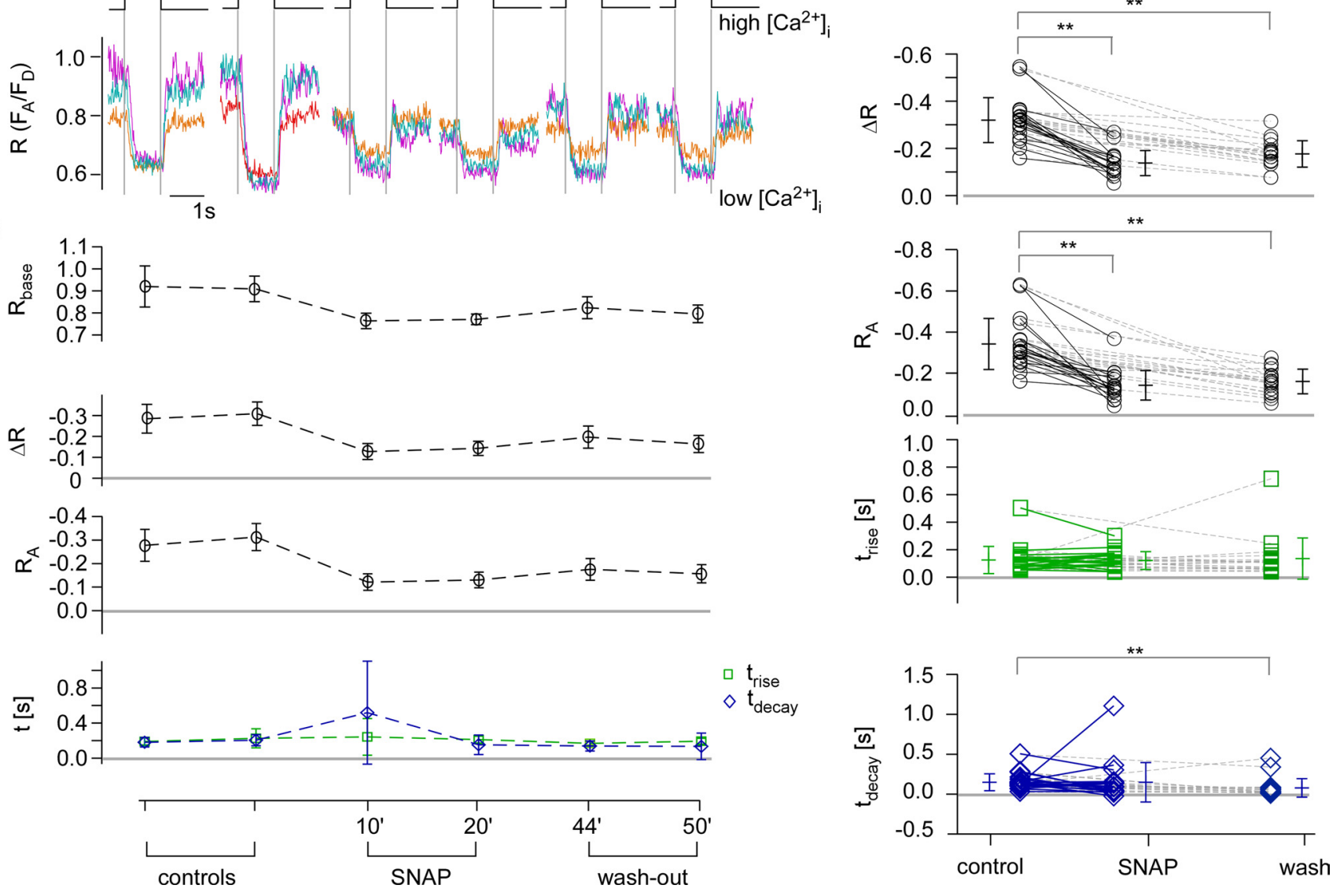

Figure 7. Effect of SNAP on the light-evoked $\mathrm{Ca}^{2+}$ response in cone terminals. A, Light-evoked $\mathrm{Ca}^{2+}$ responses in three representative cone terminals (marked by color-coded ROls) before, during, and after wash-out of SNAP, a NO donor (200 $\mu \mathrm{M}$, bath application). B, Quantification of the responses of all six cone terminals recorded in the experiment shown in $\boldsymbol{A}$. C, Summary of the SNAP effect on light-evoked $\mathrm{Ca}^{2+}$ responses for $n=19$ terminals (from 3 retinas). Wilcoxon signed test for paired samples, ${ }^{* *} p<0.01$; all others, not significant. See Figure 5 for further experimental details.

readily detectable in amacrine cells and in processes within the inner plexiform layer, but absent in the OPL (Fig. 8A-C) aside from occasional blood vessels. This lack of detectable NOS activity in the OPL makes an involvement of NO in photoreceptor synapse retrograde signaling unlikely.

Our data showed that exogenous NO decreased both resting $\left[\mathrm{Ca}^{2+}\right]$ levels and response amplitudes, suggesting a suppressive effect of NO on cone light responses. Yet, these effects are in contradiction to the classical NO-sGC pathway, in which a NOinduced sGC-dependent rise in cGMP production would result in $\mathrm{Ca}^{2+}$ influx through $\mathrm{CNG}$ channels and hence an increased $\left[\mathrm{Ca}^{2+}\right]$ level. To test whether sGC played any role in modulating cone terminal $\left[\mathrm{Ca}^{2+}\right]$, we blocked sGC using ODQ. Since the ODQ effect on resting $\left[\mathrm{Ca}^{2+}\right]$ was heterogeneous, we divided the cones into two groups, depending on whether resting $\left[\mathrm{Ca}^{2+}\right]$ level increased (group 1) or decreased (group 2). To our surprise, the prominent effect of ODQ in the majority of cones (group 1) was a small but significant and reversible increase in $R_{\text {base }}$ and $R_{\mathrm{A}}$ (Fig. $8 D$; for statistics, see Table 1 ). In the second group, $R_{\text {base }}$ tended to decrease during ODQ application, but this effect was statistically not significant. Together, this hints at a possible role of sGC in (differentially) shaping cone $\mathrm{Ca}^{2+}$ signals. However, while sGC expression was readily detected in bipolar cells of HR2.1:TN-XL mouse retina, it was undetectable in cone terminals (Fig. $8 E-G$ ), suggesting that the effects of ODQ treatment may have been indirect.

\section{Discussion}

Studying $\mathrm{Ca}^{2+}$ dynamics in cone photoreceptors has been hampered by the low numbers of cones in mice and the lack of conespecific labeling techniques with $\mathrm{Ca}^{2+}$ indicators. The successful generation of the HR2.1:TN-XL mouse for monitoring cone $\mathrm{Ca}^{2+}$ signals therefore represents a major technical advance. In this study, we demonstrate that HR2.1:TN-XL mice allow researchers to record light-evoked $\left[\mathrm{Ca}^{2+}\right]$ changes in individual cone terminals and to probe phototransduction and its diverse regulatory mechanisms with pharmacology at subcellular resolution. We further show that TN-XL-expressing cones have normal morphology and that visual function of HR2.1:TN-XL as mea- 
Table 1. Summary of pharmacological effects on light-evoked $\mathrm{Ca}^{2+}$ response in cone terminals

\begin{tabular}{|c|c|c|c|c|c|c|}
\hline & $n$ & $R_{\text {base }}$ & $\Delta R$ & $R_{\mathrm{A}}$ & $t_{\text {rise }}(\mathrm{ms})$ & $t_{\text {decay }}(\mathrm{ms})$ \\
\hline \multicolumn{7}{|l|}{ 8-pCPT-cGMP } \\
\hline Control & 17 & $1.07 \pm 0.13$ & $-0.13 \pm 0.07$ & $-0.13 \pm 0.08$ & $195 \pm 78$ & $333 \pm 432$ \\
\hline Drug & 17 & $1.85 \pm 0.25^{* *}$ & $-0.02 \pm 0.02^{* *}$ & $-0.01 \pm 0.00^{* *}$ & $89 \pm 61^{a}$ & $951 \pm 365^{a}$ \\
\hline Wash-out & 17 & $1.91 \pm 0.91^{* *}$ & $-0.17 \pm 0.11$ & $-0.17 \pm 0.16$ & $184 \pm 210$ & $642 \pm 882$ \\
\hline \multicolumn{7}{|l|}{ Zaprinast } \\
\hline Control & 15 & $0.90 \pm 0.13$ & $-0.13 \pm 0.06$ & $-0.18 \pm 0.10$ & $228 \pm 104$ & $797 \pm 369$ \\
\hline Drug & 15 & $1.38 \pm 0.33^{* *}$ & $-0.36 \pm 0.28^{* *}$ & $-0.46 \pm 0.31^{* *}$ & $375 \pm 196^{b *}$ & $932 \pm 490^{b}$ \\
\hline Wash-out & 11 & $1.23 \pm 0.10^{* *}$ & $-0.25 \pm 0.06^{* *}$ & $-0.21 \pm 0.08$ & $132 \pm 20^{*}$ & $121 \pm 156^{* *}$ \\
\hline \multicolumn{7}{|l|}{ SNAP } \\
\hline Control & 19 & $0.97 \pm 0.13$ & $-0.31 \pm 0.10$ & $-0.32 \pm 0.13$ & $196 \pm 88$ & $180 \pm 103$ \\
\hline Drug & 19 & $0.80 \pm 0.07^{* *}$ & $-0.15 \pm 0.05^{* *}$ & $-0.15 \pm 0.07^{* *}$ & $194 \pm 57$ & $180 \pm 240$ \\
\hline Wash-out & 19 & $0.81 \pm 0.05^{* *}$ & $-0.18 \pm 0.05^{* *}$ & $-0.16 \pm 0.07^{* *}$ & $206 \pm 133$ & $111 \pm 113^{* *}$ \\
\hline \multicolumn{7}{|l|}{ ODQ } \\
\hline \multicolumn{7}{|l|}{ Control } \\
\hline Group 1 & 11 & $1.13 \pm 0.22$ & $-0.25 \pm 0.16$ & $-0.25 \pm 0.12$ & $171 \pm 22$ & $380 \pm 379$ \\
\hline Group 2 & 5 & $1.36 \pm 0.13$ & $-0.37 \pm 0.05$ & $-0.27 \pm 0.07$ & $133 \pm 21$ & $360 \pm 193$ \\
\hline \multicolumn{7}{|l|}{ Drug } \\
\hline Group 1 & 11 & $1.53 \pm 0.26^{* *}$ & $-0.38 \pm 0.11^{*}$ & $-0.43 \pm 0.14^{*}$ & $190 \pm 77$ & $532 \pm 391$ \\
\hline Group 2 & 5 & $1.29 \pm 0.11$ & $-0.35 \pm 0.05$ & $-0.35 \pm 0.09$ & $169 \pm 44$ & $105 \pm 27$ \\
\hline \multicolumn{7}{|l|}{ Wash-out } \\
\hline Group 1 & 7 & $1.24 \pm 0.13$ & $-0.21 \pm 0.11^{*}$ & $-0.17 \pm 0.10^{*}$ & $215 \pm 80$ & $176 \pm 127$ \\
\hline Group 2 & 5 & $1.18 \pm 0.09$ & $-0.26 \pm 0.06$ & $-0.21 \pm 0.04$ & $139 \pm 19$ & $474 \pm 842$ \\
\hline
\end{tabular}

Parameters are presented as mean \pm SD. Significance levels are determined using the Wilcoxon signed test for paired samples (always versus control condition, ${ }^{* *} p<0.01,{ }^{*} p<0.05$; all others, not significant. $n$ is number of cells ${ }^{a} n=3 ;{ }^{b} n=11$.

sured by ERGs is indistinguishable from that recorded in wildtype littermates.

\section{HR2.1:TN-XL: a transgenic mouse line to study $\mathrm{Ca}^{2+}$ dynamics in cones}

In HR2.1:TN-XL mice, $\mathrm{Ca}^{2+}$ biosensor was absent from cone OS, which may explain why the cells maintained apparently normal phototransduction. It is conceivable that this avoided potential interferences between photopigments and TN-XL as well as $\mathrm{Ca}^{2+}$ buffering effects by the biosensor. The absence of TN-XL from OS may be due to a lack of recognition sites required for trafficking proteins to the OS (Kennedy and Malicki, 2009), restricting direct observation of $\mathrm{Ca}^{2+}$ dynamics to IS, soma, and terminal. Nevertheless, changes of OS $\left[\mathrm{Ca}^{2+}\right]$ can be at least partially inferred from $\left[\mathrm{Ca}^{2+}\right]$ changes at the synaptic terminal, since these two compartments are linked via the cone's membrane potential.

\section{Light-evoked $\mathrm{Ca}^{2+}$ response in mouse cone terminals}

To the best of our knowledge, we show for the first time that, by using HR2.1:TN-XL mice, it is possible to record light stimulusevoked $\mathrm{Ca}^{2+}$ signals from mammalian cones with little interference by the excitation laser, at subcellular resolution, and for time periods that allow lengthy pharmacological manipulations. A recent study used an adeno-associated virus (AAV)-based system to introduce the $\mathrm{Ca}^{2+}$ biosensor GCaMP3 into mouse cones (Borghuis et al., 2011, their Fig. 2F). They imaged cone terminals in whole mounts and reported large excitation laser-driven $\mathrm{Ca}^{2+}$ responses, on top of which they could elicit smaller lightstimulus-evoked responses. However, because of the different retina preparations and genetic approaches, it is difficult to compare their AAV/GCaMP3 system with the HR2.1:TN-XL line. With synthetic indicators, it is also possible to label, among other retinal neurons, photoreceptors for $\mathrm{Ca}^{2+}$ imaging in retinal slices (Mansergh et al., 2005; Babai et al., 2010), but then, at least in mice, cone signals are difficult to isolate because of the overwhelming number of rods. While isolated cones allow for better control of the experimental conditions and easy electrode access
(Szikra et al., 2009), this preparation is, of course, not suitable for measuring $\mathrm{Ca}^{2+}$ dynamics in cones interacting with their local microcircuit.

In many cones, $t_{\text {decay }}$ slowly decreased over the course of a typical $\geq 1$ h experiment. Whether this resulted from tissue damage is unclear. In some cases, the decrease in $t_{\text {decay }}$ was accompanied by the development of a $\mathrm{Ca}^{2+}$ overshoot at light-offset (Fig. $4 E_{1}$ ), reminiscent of the current undershoot reported for primate cones (Baylor et al., 1987). This undershoot was proposed to be related to delayed activation of GCs (Soo et al., 2008) by GC activating protein 2 (GCAP2), which, during light adaptation, regulates $\mathrm{GC}$ activity to restore high resting $\left[\mathrm{Ca}^{2+}\right]$ levels (Mendez et al., 2001). An alternative explanation is VGCC-dependent spiking, which has been reported for human rods (Kawai et al., 2001) and cones (Schnapf et al., 1990). In support of this theory, mouse cones sometimes showed spontaneous spike-like activity (Fig. $4 E_{2}$ ). The conditions that foster this activity and to what extent this activity is physiologically relevant remain to be investigated.

We demonstrated that HR2.1:TN-XL mice are suitable to evaluate the effects of pharmacological agents on intracellular processes in cones, with light-evoked $\mathrm{Ca}^{2+}$ response as the readout. For instance, selectively modulating the activity of $\mathrm{CNG}$ channels or PDE6 induced the expected changes in light response properties. This approach also allows screening for novel substances that affect cone $\mathrm{Ca}^{2+}$ dynamics; it could not only confirm the role of candidate factors for $\mathrm{Ca}^{2+}$ regulation in cones but may also reveal their roles in phototransduction.

\section{$\mathrm{Ca}^{2+}$ dynamics is strongly compartmentalized in mouse cones}

Direct ( $\mathrm{KCl}$ ) and indirect (cGMP analogs) depolarization as well as activation of ryanodine receptor-mediated CICR triggered large $\left[\mathrm{Ca}^{2+}\right]$ changes in the cone terminal but not in soma or IS. In the latter compartments, $\left[\mathrm{Ca}^{2+}\right]$ changes were rarely observed and rather resulted from prolonged $\mathrm{Ca}^{2+}$ influx into the terminal (and/or presumably the OS) and diffusion into the soma/IS re- 

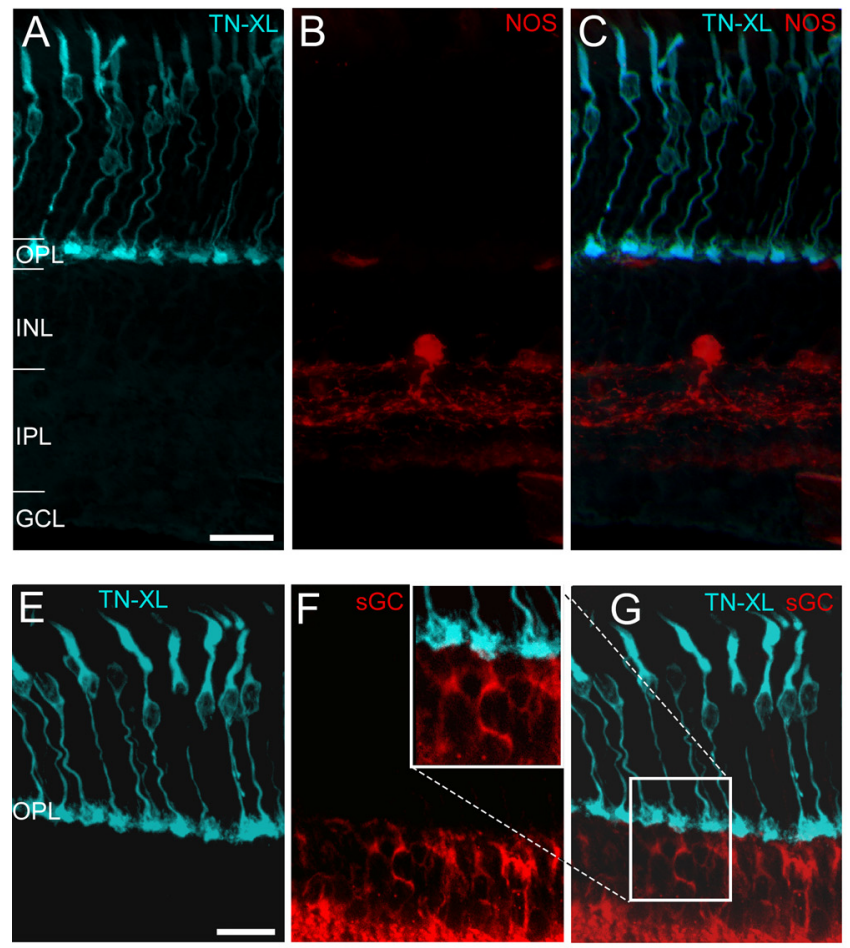
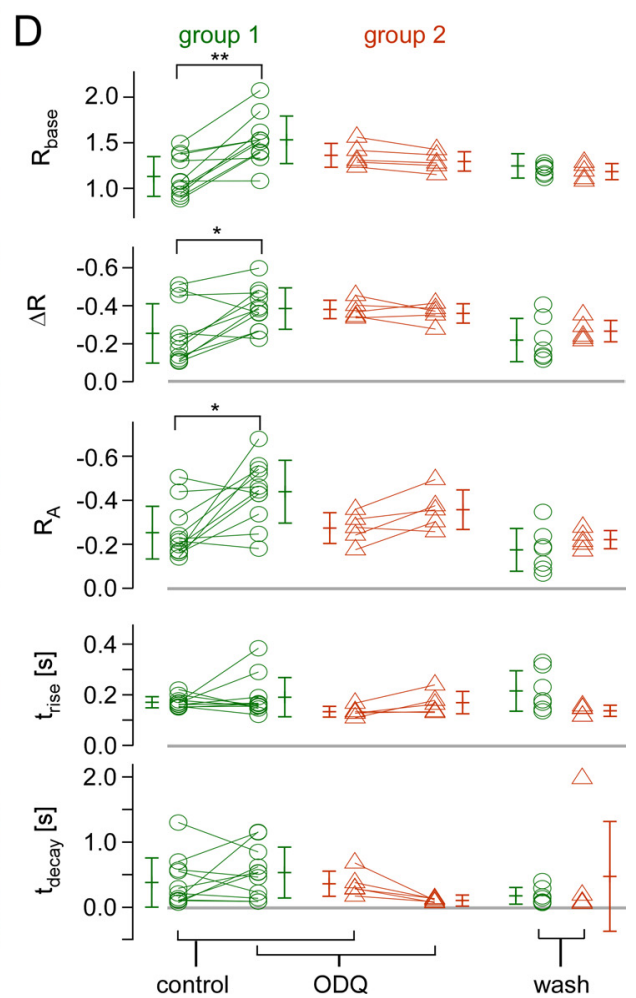

Figure 8. NOS activity assay, $\mathrm{SGC}$ staining, and the effect of $\mathrm{S} G \mathrm{C}$ blocker on light-evoked $\mathrm{Ca}^{2+}$ responses in mouse cones. $\boldsymbol{A}-\boldsymbol{C}$, Vertical section of $H R 2.1: T N-X L$ mouse retina labeled with antibodies against GFP ( $\boldsymbol{A}$, cyan) and stained using the NOS activity assay $(\boldsymbol{B}$, red). Occasional weak staining in outer retina relates to blood vessels. $\boldsymbol{D}$, Summary of the effect of ODQ, a selective sGC inhibitor, on light-evoked $\mathrm{Ca}^{2+}$ responses for $n=16$ terminals (from 3 retinas), with each symbol representing a cone (averages $\pm S D$ are given next to each symbol column). Cones were analyzed separately, depending on whether ODQ led to increase (group 1, green) or decrease (group 2, orange) in $\mathrm{Ca}^{2+}$ level $\left(R_{\text {base }}\right)$. For wash-out, only data from a total of $n=13$ cones was plotted; the remaining cells were lost (Wilcoxon signed test for paired samples, ${ }^{* *} p<0.01,{ }^{*} p<0.05$, all others, not significant). $\boldsymbol{E}-\boldsymbol{G}$, Vertical section stained for TN-XL (cyan, $\boldsymbol{D}$ ) and sGC (red, $\boldsymbol{E}$ ). $\boldsymbol{E}$, Inset, Magnification of sGC and TN-XL labeling in the OPL (from $\boldsymbol{F}$ ). INL, Inner nuclear layer; GCL, ganglion cell layer. Scale bars, $20 \mu \mathrm{m}$.

gion. This is in contrast to findings in mouse rods, where depolarization-evoked $\mathrm{Ca}^{2+}$ elevation and CICR were also observed in somata (Babai et al., 2010), suggesting differences in $\mathrm{Ca}^{2+}$ compartmentalization between rods and cones.

\section{Cone terminal $\left[\mathrm{Ca}^{2+}\right]$ is modulated by NO, but the classical NO/sGC pathway plays no major role}

In the mammalian retina, $\mathrm{NO}$ has been suggested to regulate photoreceptor light adaptation (Sato and Ohtsuka, 2010), although it is not known whether NO acts via a NO-sGC-cGMP pathway, as proposed for amphibians (Kurenny et al., 1994; Rieke and Schwartz, 1994; Savchenko et al., 1997). Since NO is membrane-permeable and has a short half-life time (Hakim et al., 1996), this pathway requires NOS activity in either cone terminals or adjacent cells. Hence, sGC and CNG channels need to be expressed in cone terminals. There are conflicting studies reporting the presence (rabbit: Haberecht et al., 1998) or absence (rat: Ding and Weinberg, 2007) of sGC in mammalian photoreceptor terminals; our immunohistochemical data supports the latter. The absence of detectable sGC levels in cone terminals is consistent with our physiological data: Instead of a $\left[\mathrm{Ca}^{2+}\right]$ increase-as would be expected for NO-mediated sGC activation-we observed a significant decrease in resting $\left[\mathrm{Ca}^{2+}\right]$ and light response amplitudes. Moreover, while a third of the tested cones displayed a small, nonsignificant decrease in resting $\left[\mathrm{Ca}^{2+}\right]$, the prominent ODQ effect was to increase resting $\left[\mathrm{Ca}^{2+}\right]$ levels in the majority of cells. The latter supports a potential role for sGC in modulating cone activity, but the effects are difficult to explain by direct action of sGC in cones. While sGC is present in cone bipolar cells (cf. Fig. $8 E-G$ ) (Ding and Weinberg, 2007), it is unclear how this could affect cone $\left[\mathrm{Ca}^{2+}\right]$. Inconsistent with a major role for the NO-sGC-cGMP pathway in mammalian cones are also the facts that CNG channels could not be detected in cone terminals (Matveev et al., 2008) and that we failed to detect NOS activity in the outer retina.

Our data clearly indicate that cone $\mathrm{Ca}^{2+}$ responses can be decreased by exogenous NO. Comparable concentrations of NO donors injected into the vitreous body in rats amplified both aand b-waves in ERGs (Sato and Ohtsuka, 2010; Vielma et al., 2010), suggesting increased photoreceptor response. This potential discrepancy may be explained by different experimental conditions and readouts, as well as by different final NO concentrations in the tissue. Note that NO as an oxidizing agent can also react with a variety of other targets depending on concentration and cell type (for review, see Lubos et al., 2008). For example, protein S-nitrosylation was suggested to underlie NO effects in photoreceptors (Vielma et al., 2010; but see Garthwaite, 2008).

In conclusion, it is unlikely that a NO-sGC-cGMP pathway plays a major role for modulating $\mathrm{Ca}^{2+}$ dynamics in mouse cones. What mechanisms underlie the observed $\mathrm{NO}$ effects and where NO might originate from remains to be seen. Nonetheless, on a more general level, our data illustrate the enormous potential of the HR2.1:TN-XL mouse in combination with 2P imaging, light stimulation, and pharmacology for functional studies of mammalian cone photoreceptors. 


\section{Further applications}

A particularly interesting application is cross-breeding of HR2.1: $T N-X L$ with cone-degeneration models, such as the CNG channel a3 subunit knock-out $\left(\mathrm{CNGa}^{-/-}\right)$(Biel et al., 1999) or the cone photoreceptor function loss-1 (cpfl1) (Chang et al., 2009) mouse. In the $\mathrm{CNGa}^{-/-}$mutant, too low $\left[\mathrm{Ca}^{2+}\right]$ levels are thought to initiate processes that eventually lead to cone death, whereas cpfl 1 cone degeneration may be triggered by $\left[\mathrm{Ca}^{2+}\right]$ overload. In the latter model, loss of cone-specific PDE6 function and the resulting elevation of cGMP levels may be the initial metabolic trigger for cone death (Trifunović et al., 2010). Intracellular cGMP targets include CNG channels (Fox et al., 1999) and cGMP-activated protein kinase G (PKG) (Hofmann et al., 2006), both of which affect intracellular $\left[\mathrm{Ca}^{2+}\right]$ either directly via CNG channels or indirectly via modulation of CNG channel activity by PKG (Castro et al., 2010). One potential link between increased $\left[\mathrm{Ca}^{2+}\right]$ level and degenerative processes in cones is the overactivation of $\mathrm{Ca}^{2+}$-dependent calpain-type proteases (Paquet-Durand et al., 2010, 2011; Trifunović et al., 2010).

The possibility to acquire light responses from a large number of cones is also exciting. This is critical to assess the functional properties of the different types of mouse cones, in particular in view of the fact that the majority of $\mathrm{M}$-cones coexpress $\mathrm{M}$ - and S-opsins, with the relative opsin contributions systematically varying along the dorsal-ventral retinal axis (Szél et al., 1992; Haverkamp et al., 2005; Wang et al., 2011).

\section{References}

Babai N, Morgans CW, Thoreson WB (2010) Calcium-induced calcium release contributes to synaptic release from mouse rod photoreceptors. Neuroscience 165:1447-1456.

Baylor DA, Nunn BJ, Schnapf JL (1987) Spectral sensitivity of cones of the monkey Macaca fascicularis. J Physiol 390:145-160.

Biel M, Seeliger M, Pfeifer A, Kohler K, Gerstner A, Ludwig A, Jaissle G, Fauser S, Zrenner E, Hofmann F (1999) Selective loss of cone function in mice lacking the cyclic nucleotide-gated channel CNG3. Proc Natl Acad Sci U S A 96:7553-7557.

Blinks JR, Olson CB, Jewell BR, Bravený P (1972) Influence of caffeine and other methylxanthines on mechanical properties of isolated mammalian heart muscle. Evidence for a dual mechanism of action. Circ Res 30:367-392.

Borghuis BG, Tian L, Xu Y, Nikonov SS, Vardi N, Zemelman BV, Looger LL (2011) Imaging light responses of targeted neuron populations in the rodent retina. J Neurosci 31:2855-2867.

Breuninger T, Puller C, Haverkamp S, Euler T (2011) Chromatic bipolar cell pathways in the mouse retina. J Neurosci 31:6504-6517.

Caride AJ, Filoteo AG, Penheiter AR, Pászty K, Enyedi A, Penniston JT (2001) Delayed activation of the plasma membrane calcium pump by a sudden increase in $\mathrm{Ca} 2+$ : fast pumps reside in fast cells. Cell Calcium 30:49-57.

Castro LR, Schittl J, Fischmeister R (2010) Feedback control through cGMP-dependent protein kinase contributes to differential regulation and compartmentation of cGMP in rat cardiac myocytes. Circ Res 107:1232-1240.

Chang B, Grau T, Dangel S, Hurd R, Jurklies B, Sener EC, Andreasson S, Dollfus H, Baumann B, Bolz S, Artemyev N, Kohl S, Heckenlively J, Wissinger B (2009) A homologous genetic basis of the murine cpfll mutant and human achromatopsia linked to mutations in the PDE6C gene. Proc Natl Acad Sci U S A 106:19581-19586.

Chang GQ, Hao Y, Wong F (1993) Apoptosis: final common pathway of photoreceptor death in rd, rds, and rhodopsin mutant mice. Neuron 11:595-605.

Choi SY, Borghuis BG, Borghuis B, Rea R, Levitan ES, Sterling P, Kramer RH (2005) Encoding light intensity by the cone photoreceptor synapse. Neuron 48:555-562.

Choi SY, Jackman S, Thoreson WB, Kramer RH (2008) Light regulation of $\mathrm{Ca} 2+$ in the cone photoreceptor synaptic terminal. Vis Neurosci 25:693-700.
Denk W, Detwiler PB (1999) Optical recording of light-evoked calcium signals in the functionally intact retina. Proc Natl Acad Sci U S A 96:7035-7040.

Denk W, Strickler JH, Webb WW (1990) Two-photon laser scanning fluorescence microscopy. Science 248:73-76.

Ding JD, Weinberg RJ (2007) Distribution of soluble guanylyl cyclase in rat retina. J Comp Neurol 502:734-745.

Dreosti E, Odermatt B, Dorostkar MM, Lagnado L (2009) A genetically encoded reporter of synaptic activity in vivo. Nat Methods 6:883-889.

Euler T, Hausselt SE, Margolis DJ, Breuninger T, Castell X, Detwiler PB, Denk W (2009) Eyecup scope-optical recordings of light stimulus-evoked fluorescence signals in the retina. Pflugers Arch 457:1393-1414.

Fain GL, Matthews HR, Cornwall MC, Koutalos Y (2001) Adaptation in vertebrate photoreceptors. Physiol Rev 81:117-151.

Fox DA, Poblenz AT, He L (1999) Calcium overload triggers rod photoreceptor apoptotic cell death in chemical-induced and inherited retinal degenerations. Ann N Y Acad Sci 893:282-285.

Garthwaite J (2008) Concepts of neural nitric oxide-mediated transmission. Eur J Neurosci 27:2783-2802.

Gordon JW, Ruddle FH (1981) Integration and stable germ line transmission of genes injected into mouse pronuclei. Science 214:1244-1246.

Haberecht MF, Schmidt HH, Mills SL, SC, Nakane M, Redburn-Johnson DA (1998) Localization of nitric oxide synthase, NADPH diaphorase and soluble guanylyl cyclase in adult rabbit retina. Vis Neurosci 15:881-890.

Hakim TS, Sugimori K, Camporesi EM, Anderson G (1996) Half-life of nitric oxide in aqueous solutions with and without haemoglobin. Physiol Meas 17:267-277.

Haverkamp S, Wässle H, Duebel J, Kuner T, Augustine GJ, Feng G, Euler T (2005) The primordial, blue-cone color system of the mouse retina. J Neurosci 25:5438-5445.

Hendel T, Mank M, Schnell B, Griesbeck O, Borst A, Reiff DF (2008) Fluorescence changes of genetic calcium indicators and OGB-1 correlated with neural activity and calcium in vivo and in vitro. J Neurosci 28:7399-7411.

Hofmann F, Feil R, Kleppisch T, Schlossmann J (2006) Function of cGMPdependent protein kinases as revealed by gene deletion. Physiological Reviews 86:1-23.

Hope BT, Michael GJ, Knigge KM, Vincent SR (1991) Neuronal NADPH diaphorase is a nitric oxide synthase. Proc Natl Acad Sci USA 88:2811-2814.

Hurwitz RL, Bunt-Milam AH, Chang ML, Beavo JA (1985) cGMP phosphodiesterase in rod and cone outer segments of the retina. J Biol Chem 260:568-573.

Jacobs GH, Neitz J, Deegan JF 2nd (1991) Retinal receptors in rodents maximally sensitive to ultraviolet light. Nature 353:655-656.

Johnson JE Jr, Perkins GA, Giddabasappa A, Chaney S, Xiao W, White AD, Brown JM, Waggoner J, Ellisman MH, Fox DA (2007) Spatiotemporal regulation of ATP and $\mathrm{Ca} 2+$ dynamics in vertebrate rod and cone ribbon synapses. Mol Vis 13:887-919.

Kawai F, Horiguchi M, Suzuki H, Miyachi E (2001) Na(+) action potentials in human photoreceptors. Neuron 30:451-458.

Kennedy B, Malicki J (2009) What drives cell morphogenesis: a look inside the vertebrate photoreceptor. Developmental Dynamics 238:2115-2138.

Korenbrot JI (1995) Ca2 + flux in retinal rod and cone outer segments: differences in $\mathrm{Ca} 2+$ selectivity of the cGMP-gated ion channels and $\mathrm{Ca} 2+$ clearance rates. Cell Calcium 18:285-300.

Koutalos Y, Yau KW (1996) Regulation of sensitivity in vertebrate rod photoreceptors by calcium. Trends in neurosciences 19:73-81.

Krishna VR, Alexander KR, Peachey NS (2002) Temporal properties of the mouse cone electroretinogram. J Neurophysiol 87:42-48.

Krizaj D (2005) Compartmentalization of calcium entry pathways in mouse rods. Eur J Neurosci 22:3292-3296.

Krizaj D, Copenhagen DR (2002) Calcium regulation in photoreceptors. Front Biosci 7:d2023-2044.

Kurenny DE, Moroz LL, Turner RW, Sharkey KA, Barnes S (1994) Modulation of ion channels in rod photoreceptors by nitric oxide. Neuron 13:315-324.

Lubos E, Handy DE, Loscalzo J (2008) Role of oxidative stress and nitric oxide in atherothrombosis. Front Biosci 13:5323-5344.

Mank M, Reiff DF, Heim N, Friedrich MW, Borst A, Griesbeck O (2006) A FRET-based calcium biosensor with fast signal kinetics and high fluorescence change. Biophys J 90:1790-1796. 
Mansergh F, Orton NC, Vessey JP, Lalonde MR, Stell WK, Tremblay F, Barnes S, Rancourt DE, Bech-Hansen NT (2005) Mutation of the calcium channel gene Cacnalf disrupts calcium signaling, synaptic transmission and cellular organization in mouse retina. Hum Mol Genet 14:3035-3046.

Marmor MF, Holder GE, Seeliger MW, Yamamoto S (2004) Standard for clinical electroretinography (2004 update). Doc Ophthalmol 108:107-114.

Matveev AV, Quiambao AB, Browning Fitzgerald J, Ding XQ (2008) Native cone photoreceptor cyclic nucleotide-gated channel is a heterotetrameric complex comprising both CNGA3 and CNGB3: a study using the conedominant retina of Nrl-/- mice. J Neurochem 106:2042-2055.

Mendez A, Burns ME, Sokal I, Dizhoor AM, Baehr W, Palczewski K, Baylor DA, Chen J (2001) Role of guanylate cyclase-activating proteins (GCAPs) in setting the flash sensitivity of rod photoreceptors. Proc Natl Acad Sci U S A 98:9948-9953.

Morgans CW, Bayley PR, Oesch NW, Ren G, Akileswaran L, Taylor WR (2005) Photoreceptor calcium channels: insight from night blindness. Vis Neurosci 22:561-568.

Nikonov SS, Kholodenko R, Lem J, Pugh EN Jr (2006) Physiological features of the $\mathrm{S}$ - and $\mathrm{M}$-cone photoreceptors of wild-type mice from singlecell recordings. J Gen Physiol 127:359-374.

Paquet-Durand F, Sanges D, McCall J, Silva J, van Veen T, Marigo V, Ekström P (2010) Photoreceptor rescue and toxicity induced by different calpain inhibitors. J Neurochem 115:930-940.

Paquet-Durand F, Beck S, Michalakis S, Goldmann T, Huber G, Mühlfriedel R, Trifunović D, Fischer MD, Fahl E, Duetsch G, Becirovic E, Wolfrum U, van Veen T, Biel M, Tanimoto N, Seeliger MW (2011) A key role for cyclic nucleotide gated (CNG) channels in cGMP-related retinitis pigmentosa. Hum Mol Genet 20:941-947.

Pugh EN Jr, Lamb TD (1993) Amplification and kinetics of the activation steps in phototransduction. Biochim Biophys Acta 1141:111-149.

Rieke F, Schwartz EA (1994) A cgmp-gated current can control exocytosis at cone synapses. Neuron 13:863-873.

Rink TJ, Pozzan T (1985) Using quin2 in cell suspensions. Cell calcium 6:133-144.

Sahaboglu A, Tanimoto N, Kaur J, Sancho-Pelluz J, Huber G, Fahl E, ArangoGonzalez B, Zrenner E, Ekström P, Löwenheim H, Seeliger M, PaquetDurand F (2010) PARP1 gene knock-out increases resistance to retinal degeneration without affecting retinal function. PloS One 5:e15495.

Sancho-Pelluz J, Arango-Gonzalez B, Kustermann S, Romero FJ, van Veen T, Zrenner E, Ekström P, Paquet-Durand F (2008) Photoreceptor cell death mechanisms in inherited retinal degeneration. Mol Neurobiol $38: 253-269$

Sato M, Ohtsuka T (2010) Opposite effects of nitric oxide on rod and cone photoreceptors of rat retina in situ. Neurosci Lett 473:62-66.

Savchenko A, Barnes S, Kramer RH (1997) Cyclic-nucleotide-gated channels mediate synaptic feedback by nitric oxide. Nature 390:694-698.

Schnapf JL, Nunn BJ, Meister M, Baylor DA (1990) Visual transduction in cones of the monkey Macaca fascicularis. J Physiol 427:681-713.

Seeliger MW, Grimm C, Ståhlberg F, Friedburg C, Jaissle G, Zrenner E, Guo H, Remé CE, Humphries P, Hofmann F, Biel M, Fariss RN, Redmond TM, Wenzel A (2001) New views on RPE65 deficiency: the rod system is the source of vision in a mouse model of Leber congenital amaurosis. Nat Genet 29:70-74.

Sheng Z, Choi SY, Dharia A, Li J, Sterling P, Kramer RH (2007) Synaptic $\mathrm{Ca} 2+$ in darkness is lower in rods than cones, causing slower tonic release of vesicles. J Neurosci 27:5033-5042.

Soo FS, Detwiler PB, Rieke F (2008) Light adaptation in salamander L-cone photoreceptors. J Neurosci 28:1331-1342.

Sterling P, Matthews G (2005) Structure and function of ribbon synapses. Trends Neurosci 28:20-29.

Stockman A, Sharpe LT (2000) The spectral sensitivities of the middle- and long-wavelength-sensitive cones derived from measurements in observers of known genotype. Vision Res 40:1711-1737.

Szél A, Röhlich P, Caffé AR, Juliusson B, Aguirre G, Van Veen T (1992) Unique topographic separation of two spectral classes of cones in the mouse retina. J Comp Neurol 325:327-342.

Szikra T, Krizaj D (2006) The dynamic range and domain-specific signals of intracellular calcium in photoreceptors. Neuroscience 141:143-155.

Szikra T, Barabas P, Bartoletti TM, Huang W, Akopian A, Thoreson WB, Krizaj D (2009) Calcium homeostasis and cone signaling are regulated by interactions between calcium stores and plasma membrane ion channels. PloS One 4:e6723.

Tanimoto N, Muehlfriedel RL, Fischer MD, Fahl E, Humphries P, Biel M, Seeliger MW (2009) Vision tests in the mouse: functional phenotyping with electroretinography. Front Biosci 14:2730-2737.

Taylor WR, Morgans C (1998) Localization and properties of voltage-gated calcium channels in cone photoreceptors of Tupaia belangeri. Vis Neurosci 15:541-552.

Trifunović D, Dengler K, Michalakis S, Zrenner E, Wissinger B, PaquetDurand F (2010) cGMP-dependent cone photoreceptor degeneration in the cpfl1 mouse retina. J Comp Neurol 518:3604-3617.

Tsien RY (1981) A non-disruptive technique for loading calcium buffers and indicators into cells. Nature 290:527-528.

Tsien RY, Pozzan T, Rink TJ (1982) Calcium homeostasis in intact lymphocytes: cytoplasmic free calcium monitored with a new, intracellularly trapped fluorescent indicator. J Cell Biol 94:325-334.

Vielma A, Delgado L, Elgueta C, Osorio R, Palacios AG, Schmachtenberg O (2010) Nitric oxide amplifies the rat electroretinogram. Exp Eye Res 91:700-709.

Wang Y, Macke JP, Merbs SL, Zack DJ, Klaunberg B, Bennett J, Gearhart J, Nathans J (1992) A locus control region adjacent to the human red and green visual pigment genes. Neuron 9:429-440.

Wang YV, Weick M, Demb JB (2011) Spectral and temporal sensitivity of cone-mediated responses in mouse retinal ganglion cells. J Neurosci 31:7670-7681.

Wei JY, Cohen ED, Genieser HG, Barnstable CJ (1998) Substituted cGMP analogs can act as selective agonists of the rod photoreceptor cGMP-gated cation channel. J Mol Neurosci 10:53-64.

Werblin FS (1978) Transmission along and between rods in the tiger salamander retina. J Physiol 280:449-470.

Zhang X, Feng Q, Cote RH (2005) Efficacy and selectivity of phosphodiesterase-targeted drugs in inhibiting photoreceptor phosphodiesterase (PDE6) in retinal photoreceptors. Investigative ophthalmology and visual science 46:3060-3066. 